\title{
The Effects of Age and Long-Term Endurance Training on VO2 Kinetics
}

Tyler M. Grey, The University of Western Ontario

Supervisor: Donald H. Paterson, The University of Western Ontario

A thesis submitted in partial fulfillment of the requirements for the Master of Science degree in Kinesiology

(C) Tyler M. Grey 2014

Follow this and additional works at: https://ir.lib.uwo.ca/etd

Part of the Kinesiology Commons

\section{Recommended Citation}

Grey, Tyler M., "The Effects of Age and Long-Term Endurance Training on VO2 Kinetics" (2014). Electronic Thesis and Dissertation Repository. 1976.

https://ir.lib.uwo.ca/etd/1976

This Dissertation/Thesis is brought to you for free and open access by Scholarship@Western. It has been accepted for inclusion in Electronic Thesis and Dissertation Repository by an authorized administrator of Scholarship@Western. For more information, please contact wlswadmin@uwo.ca. 


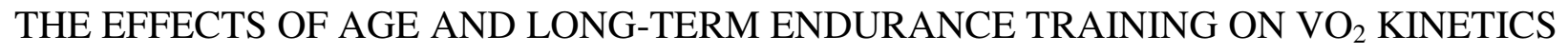

(Thesis format: Integrated Article)

by

Tyler M. Grey

Graduate Program in Kinesiology

A thesis submitted in partial fulfillment

of the requirements for the degree of

Master of Science

The School of Graduate and Postdoctoral Studies

The University of Western Ontario

London, Ontario, Canada

(C) Tyler Grey 2014 


\begin{abstract}
The kinetics of the adjustment of pulmonary oxygen uptake $\left(\mathrm{VO}_{2}\right)$ was examined during step transitions from $20 \mathrm{~W}$ to moderate-intensity cycling in young (Y), middle-aged (M), and older (O) endurance trained and untrained men. $\mathrm{VO}_{2 \mathrm{p}}$ was measured breath-by-breath and changes in deoxygenated hemoglobin $([\mathrm{HHb}])$ were measured by near-infrared spectroscopy. $\mathrm{VO}_{2 \mathrm{p}}$ and $[\mathrm{HHb}]$ were modeled with a monoexponential model. The kinetic time constant for $\mathrm{VO}_{2}\left(\tau \mathrm{VO}_{2 \mathrm{p}}\right)$ was not different across age-groups $(\mathrm{P}>0.05)$ in the trained group $(17 \pm 8,18 \pm 5$, and $20 \pm 5 \mathrm{~s}$, in $\mathrm{Y}, \mathrm{M}$, and $\mathrm{O}$, respectively). For untrained, $\tau \mathrm{VO}_{2 \mathrm{p}}$ was greater $(\mathrm{P}<0.05)$ only in the $\mathrm{O}(26 \pm 7$, $24 \pm 7$, and $42 \pm 11 \mathrm{~s}$ for $\mathrm{Y}, \mathrm{M}$, and $\mathrm{O}$, respectively). The overall adjustment of [HHb] was faster than $\tau \mathrm{VO}_{2 \mathrm{p}}$ in $\mathrm{O}$ untrained, resulting in an $[\mathrm{HHb}] / \mathrm{VO}_{2 \mathrm{p}}$ "overshoot" during the exercise transient; this may reflect a microvascular blood flow limitation. The present study suggests that long-term endurance training can abolish the age-related slowing of $\tau \mathrm{VO}_{2 p}$ via improved matching of local $\mathrm{O}_{2}$ delivery to muscle $\mathrm{VO}_{2}$.
\end{abstract}

Keywords: $\mathrm{O}_{2}$ uptake kinetics, aging, trained, near-infrared spectroscopy 


\section{CO-AUTHORSHIP STATEMENT}

This study was designed by M.D. Spencer, T.M. Grey and D.H. Paterson with input from the advisory committee (J.M. Kowalchuk and G.R. Belfry). The majority of the data were collected and analyzed by T.M. Grey with the assistance of M.D. Spencer and J.M. Murias. T.M. Grey wrote the original manuscript for the study. D.H. Paterson provided financial support and editorial feedback. 


\section{ACKNOWLEDGEMENTS}

To Dr. Don Paterson - Sometimes it seemed like you knew what I was going to ask before I even stepped into your office. You're incredibly knowledgeable, approachable, and were incredibly helpful in guiding me through this amazing experience. To Dr. John Kowalchuk - Thank you for all your help and providing me with a foundation for understanding exercise physiology.

To Dr. Matt Spencer - It is safe to say that I would not be half the researcher I am today without your guidance and undying patience. I started volunteering in this lab in 2010 and right away you took me under your wing and taught me everything I know. When you left the lab to face larger challenges in Japan, Texas and Calgary, you remained my mentor and continued to teach me new things about myself and what it means to be a researcher. Your meticulous attention to detail and ability to explain concepts thoroughly are just a few of your best traits. I don't say this often enough, but I have no doubt that you will become a very influential figure in your research and teaching career. To Dr. Juan Murias - your "always open door" attitude to me has truly helped me out when I needed it the most. Your ability to teach even the "simplest of minds," (i.e. myself) is one of your greatest attributes. Matt has always had kind words to say about you and it would be impossible to refute him on any of them. You two are truly my inspiration for my future endeavors.

To my labmates and friends: Kait McLay, Josh Nederveen, Dan Keir, Taylor Robertson, John Leckie, and Lorenzo Love - thanks for always being available when I needed help, whether it was a simple question or guiding me through the struggles of our new software, you made everyday at the lab more enjoyable. To my fiancée Ashley - thank you for supporting me when I came home late after a long day in the lab. I appreciate the many Starbucks dates that we went on, even though I did not get much work done sitting next to you, it never feels like work when I'm with you. Finally, to my family, for supporting me through my seven years at Western and never questioning my motives along the way. 


\section{TABLE OF CONTENTS}

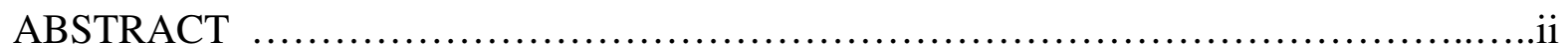

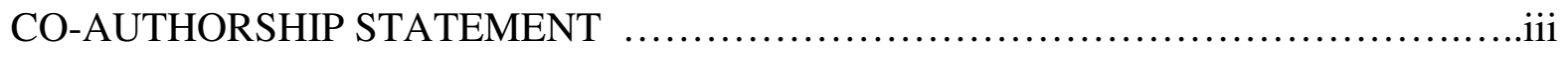

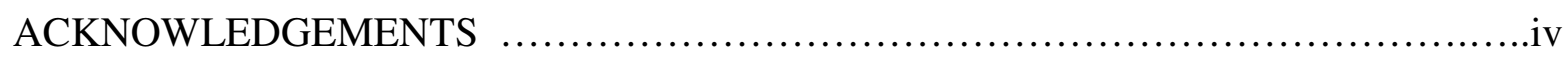

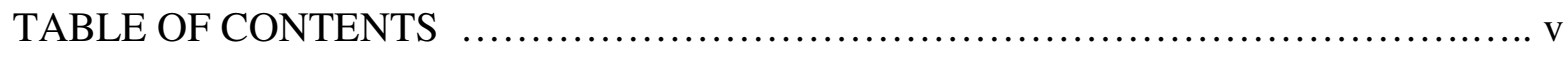

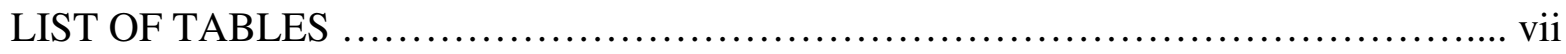

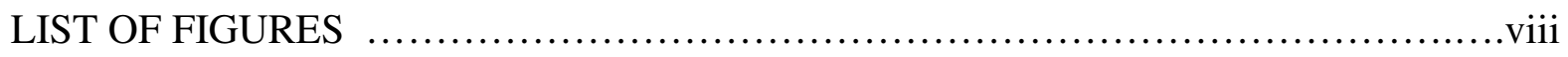

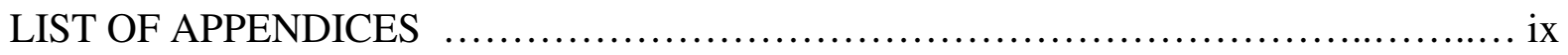

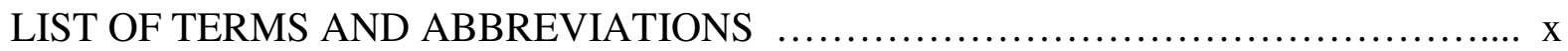

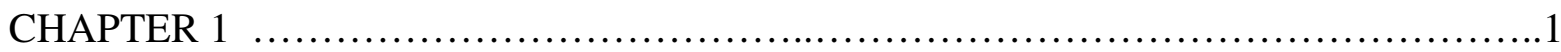

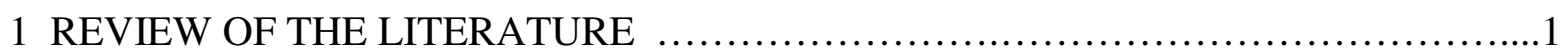

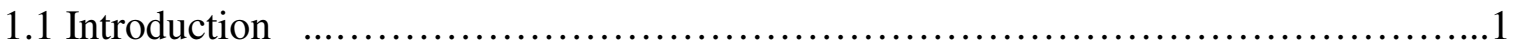

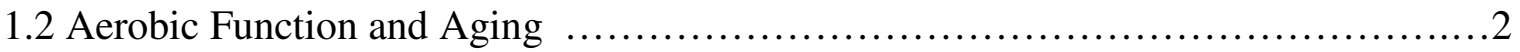

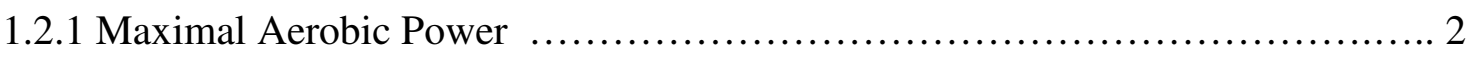

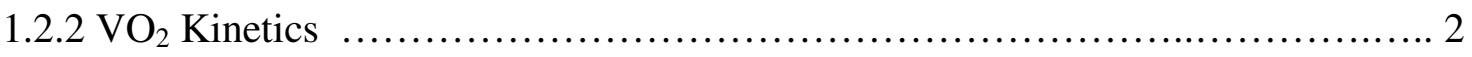

1.3 Aerobic Function and Aging in Endurance Trained …........................... 7

1.3.1 Maximal Aerobic Power .................................................. 7

1.3.2 $\mathrm{VO}_{2}$ Kinetics ......................................................... 8

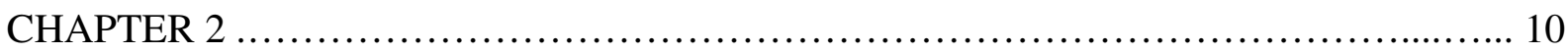

2 THE EFFECTS OF AGE AND LONG-TERM ENDURANCE TRAINING ON $\mathrm{VO}_{2}$

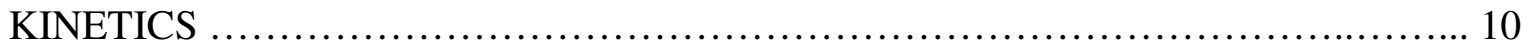

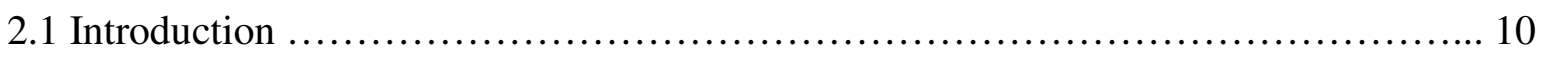

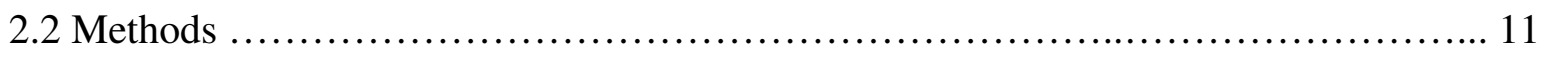

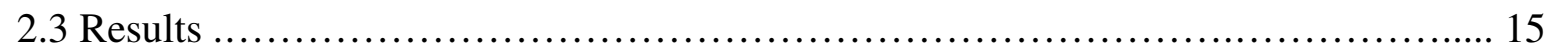

2.4 Discussion ....................................................................... 25 
REFERENCE LIST

APPENDIX A: Ethics Approval Notice ............................................... 41

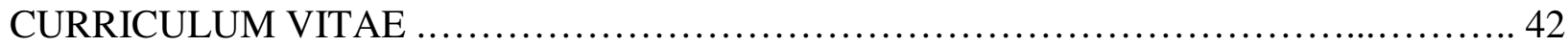




\section{LIST OF TABLES}

\section{Table}

1 Subject characteristics and peak exercise responses

2 Group average training program data for the endurance-trained men

$3 \mathrm{VO}_{2 \mathrm{p}}$ kinetic parameters for the transition to moderate-intensity exercise

19

$4 \quad[\mathrm{HHb}]$ kinetic parameters for the transition to moderate-intensity exercise 


\section{LIST OF FIGURES}

Figure

1 Individual and average group $\mathrm{VO}_{2}$ max values.

$2 \quad$ Individual and average group $\tau \mathrm{VO}_{2 \mathrm{p}}$ values

3 Group mean profiles for the adjustment of [HHb] and $\mathrm{VO}_{2 p}$ during the step transition to MOD

4

\section{Description}

Page

21

22

23

24 


\section{LIST OF APPENDICES}

Appendix

A

Ethics Approval Notice
Page

41 


\section{LIST OF TERMS AND ABBREVIATIONS}

[ADP] - adenosine diphosphate concentration

AMP - amplitude of the response

[ATP] - adenosine triphosphate concentration

a- $\mathrm{vO}_{2}$ difference - difference between arterial and venous oxygen content

BSLN - baseline

$\mathrm{CO}_{2}$ - carbon dioxide

DCA - dichloroacetate

ETC - Electron transport chain

$\mathrm{F}_{\mathrm{i}} \mathrm{O}_{2}-$ fraction of inspired $\mathrm{O}_{2}$

$\left[\mathrm{HbO}_{2}\right]$ - oxyhemoglobin, measure of muscle oxygenation concentration

$[\mathrm{HHb}]$ - deoxyhemoglobin, measure of muscle deoxygenation concentration

HR - heart rate

$\theta_{\mathrm{L}}-$ lactate threshold

$\mathrm{M}$ - middle-aged

MOD - moderate intensity exercise domain

MT - middle-aged trained group

MuT - middle-aged untrained group

NIRS - near infra-red spectroscopy

NOS - nitric oxide synthase

$\mathrm{O}$ - older

$\mathrm{O}_{2}$ - oxygen

OT - older trained group

OuT - older untrained group

$\mathrm{PaO}_{2}$ - arterial partial pressure of $\mathrm{O}_{2}$ 
$\mathrm{PCO}_{2}$ - partial pressure of carbon dioxide

$[\mathrm{PCr}]$ - phosphocreatine concentration

PDH - pyruvate dehydrogenase

$\mathrm{PO}_{2}$ - partial pressure of oxygen

Q - cardiac output

RER - respiratory exchange ratio

SD - standard deviations

$\tau$ - time constant; time required to attain $63 \%$ of the steady-state response

$\tau^{\prime}-$ effective time constant $(\tau+$ TD)

TCA - tricarboxylic acid cycle

TD - time delay

$\mathrm{VCO}_{2}$ - volume of carbon dioxide

$\mathrm{VO}_{2}$ - volume of oxygen uptake

$\mathrm{VO}_{2} \mathrm{max}$ - maximal oxygen uptake; measure of maximal aerobic power

$\mathrm{VO}_{2 \mathrm{~m}}-$ muscle oxygen uptake

$\mathrm{VO}_{2 p}$ - pulmonary oxygen uptake

W - watts

$\mathrm{WR}$ - work rate

Y - young

YT - young trained group

YuT - young untrained group 


\section{CHAPTER 1}

\section{REVIEW OF THE LITERATURE \\ 1.1 INTRODUCTION}

The study of $\mathrm{VO}_{2}$ (volume of oxygen $\left(\mathrm{O}_{2}\right)$ uptake) and its regulation is important as oxidative metabolism is the principle means by which the human organism generates energy to do work in all but the most short-lived activities. $\mathrm{VO}_{2}$ is measured as the difference between the volume of $\mathrm{O}_{2}$ inspired and $\mathrm{O}_{2}$ expired at the mouth. This pulmonary measure allows us to determine the relative level of exertion at the exercising muscle. The present thesis focuses on comparisons of aerobic function with aging (young, middle-aged, and older), in both endurance trained and untrained men. Two important aerobic functions of the cardiovascular system are: 1) maximal aerobic power, and 2) rate of adjustment of $\mathrm{O}_{2}$ uptake and utilization $\left(\mathrm{VO}_{2}\right.$ kinetics) in response to a change in work rate (energy demand) from baseline to sub-maximal exercise. Maximal aerobic power $\left(\mathrm{VO}_{2} \mathrm{max}\right)$ represents the maximum capacity of the whole body to transport and use oxygen during incremental exercise to fatigue; thus, the cardiorespiratory fitness of an individual is heavily determined by an individual's maximal $\mathrm{VO}_{2}$ uptake. The second measure of aerobic function, $\mathrm{VO}_{2}$ kinetics, is the measure of the rate of adjustment of $\mathrm{O}_{2}$ uptake and utilization at the muscle during sub-maximal exercise. Whereas $\mathrm{VO}_{2}$ max relies heavily on bulk blood flow (cardiac output) and $\mathrm{O}_{2}$ delivery to the exercising muscle, the $\mathrm{VO}_{2}$ kinetic profile is determined mostly by: a) microvascular $\mathrm{O}_{2}$ delivery and b) metabolic substrate utilization and enzymatic activation at the muscle. Thus, the $\mathrm{VO}_{2}$ kinetic profile alludes to the physiological mechanisms active at the exercising muscle that regulate $\mathrm{O}_{2}$ uptake during the ontransient to sub-maximal exercise. A faster $\mathrm{VO}_{2}$ kinetic profile represents the body's ability to obtain more energy from aerobic metabolism (an essentially endless supply of energy) earlier, with less reliance on anaerobic metabolism (which produces fatigue-causing metabolites). Therefore, for many performance outcomes, ranging from those of endurance athletes to that of older adults accomplishing daily tasks, it is advantageous to have a faster $\mathrm{VO}_{2}$ kinetic profile. In the end, $\mathrm{VO}_{2} \max$ and $\mathrm{VO}_{2}$ kinetics are two different measures of aerobic function and both have differing underlying mechanisms that govern the response to exercise. 


\subsection{AEROBIC FUNCTION AND AGING}

\subsubsection{Maximal Aerobic Power}

Maximal aerobic function $\left(\mathrm{VO}_{2} \mathrm{max}\right)$ can be defined by the Fick Equation (equation 1):

$\mathrm{VO}_{2} \max =\mathrm{Q} \times\left(\mathrm{a}-\mathrm{vO}_{2}\right.$ difference $)$

Equation 1

where $\mathrm{Q}$ is cardiac output (product of heart rate (HR) and stroke volume) or tissue blood flow, and a- $\mathrm{vO}_{2}$ difference is the difference between arterial and venous $\mathrm{O}_{2}$ content and characterizes the tissue's ability to extract oxygen from the circulating blood. Thus, $\mathrm{VO}_{2} \mathrm{max}$ is determined by both the capacity for oxygen delivery and for oxygen utilization. As we age the functional capacity of the cardiovascular system decreases, resulting in a decline in $\mathrm{VO}_{2} \mathrm{max}$ (Betik \& Hepple, 2008). The rate of decline per decade in healthy sedentary men appears to range between 10 to 15\% (Paterson \& Cunningham, 1999; Paterson et al., 1999; Rogers et al., 1990;

Stathokostas et al., 2004; Trappe et al., 1996), whereas females range from $\sim 7$ to $12 \%$ (Fitzgerald et al., 1997; Paterson et al., 1999; Stathokostas et al., 2004; Tanaka et al., 1997). The decline in $\mathrm{VO}_{2}$ max with age is most likely due to a combination of a compromised capacity for both oxygen delivery and oxygen utilization (Murias et al., 2011a). Thus, the decline can partially be attributed to a decrease in $\mathrm{Q}$, which some researchers have attributed to the natural decline in maximal heart rate (HR) (Fuchi et al., 1989; Pimental et al., 2003). However, Hagberg et al. (1985) and others (Beere et al., 1999; Rogers et al., 1990; Trappe et al., 1996) have found that in healthy older individuals the decline in $\mathrm{VO}_{2}$ max may be attributed to both a decline in $\mathrm{HR}$ (and consequently Q) and a- $\mathrm{vO}_{2}$ difference. Nevertheless, the decline in $\mathrm{VO}_{2}$ max with age is generally determined by the decline in Q (Rowell, 1974).

\subsection{2 $\mathrm{VO}_{2}$ Kinetics}

Physiology and Measurement of Oxygen Uptake Kinetics

Immediately following the onset of exercise, a higher adenosine triphosphate (ATP) requirement exists within the active muscles (Rossiter et al., 1999). Whereas ATP demand increases instantaneously, indicators of oxidative phosphorylation such as muscle oxygen uptake $\left(\mathrm{VO}_{2 \mathrm{~m}}\right)$ and pulmonary oxygen uptake $\left(\mathrm{VO}_{2 \mathrm{p}}\right)$ have been observed to be relatively slow (Grassi et al., 1996); thus, the remaining energy demand is met by phosphocreatine (PCr) hydrolysis and, to a lesser extent, anaerobic glycolysis/glycogenolysis (Whipp \& Wasserman, 1972).

Furthermore, if the exercising work rate (WR) is to be maintained for extended periods of time, the prolonged ATP demand must be met through oxidative phosphorylation. Given that the 
exercise transition remains below the lactate threshold $\left(\theta_{\mathrm{L}}\right)$ and within the moderate-intensity domain (MOD), $\mathrm{VO}_{2}$ will illustrate a multi-phase exponential response to meet the ATP demand. Thus, a delay is created between the demand for ATP (instantaneous) and the matched production of ATP through oxidative phosphorylation; when the production of ATP matches the demand for ATP, a steady-state will be attained (Whipp, 1971). The exponential increase in $\mathrm{VO}_{2}$ before steady-state is reached (usually within 120 to 240 seconds in MOD (Whipp, 1971)), is referred to as phase II $\mathrm{VO}_{2}$, which can be described quantitatively with a time constant $(\tau)$.

The $\tau$ of the phase II $\mathrm{VO}_{2}\left(\tau \mathrm{VO}_{2}\right)$ response from the onset of exercise represents the time it takes to achieve $63 \%$ of $\Delta \mathrm{VO}_{2}$ (the change in $\mathrm{VO}_{2}$ to steady state at new work rate). The response may also be characterized by its overall amplitude, which is the change in $\mathrm{VO}_{2}$ from baseline to the steady-state achieved following the exercise transition. Knowledge of both the amplitude and $\tau \mathrm{VO}_{2}$ allows for the estimation of the $\mathrm{O}_{2}$ deficit, which reflects the muscle's reliance on non-oxidative pathways (PCr hydrolysis and glycolysis/glycogenolysis) for energy production during exercise transitions to MOD (DeLorey et al., 2007; Paterson \& Whipp, 1991). Therefore, an advantage exists with lesser $\tau \mathrm{VO}_{2}$ values as the transition to steady-state is shortened and there is a reduced reliance on non-oxidative pathways.

The implication that measures of $\mathrm{VO}_{2}$ directly reflect the measures of oxygen uptake at the muscle $\left(\mathrm{VO}_{2 \mathrm{~m}}\right)$ has been confirmed. Researchers have used a few different techniques to assess the approximation of human $\mathrm{VO}_{2 \mathrm{~m}}$ (Grassi et al., 1996; Koga et al., 2005), the most common measure being $\mathrm{VO}_{2 \mathrm{p}}$. Grassi et al. (1996) observed the $\mathrm{VO}_{2 \mathrm{p}}$ response to be within $\sim 10 \%$ of $\mathrm{VO}_{2}$ in vivo via invasive measures of conduit artery blood flow and a- $\mathrm{vO}_{2}$ difference across the exercised muscle. Magnetic resonance spectroscopy has also been used to show: a) a tight coupling between [PCr] breakdown and $\mathrm{VO}_{2 \mathrm{~m}}$ and b) similar kinetic responses between [PCr] breakdown and the adjustment of $\mathrm{VO}_{2 p}$ (Chilibeck et al., 1998; McCreary et al., 1996; Rossiter et al., 1999). Therefore, the non-invasive measures of $\mathrm{VO}_{2 \mathrm{p}}$ are validated to be useful for investigating the regulation of $\mathrm{O}_{2}$ consumption at the level of the muscle.

Pulmonary measures of $\mathrm{VO}_{2}$ are collected breath-by-breath during the step transitions in work rate. Data from three continuous transitions (Spencer et al., 2011) of baseline to MOD are interpolated to $1 \mathrm{~s}$ intervals, time-aligned, and ensemble averaged to yield a single response. The $\mathrm{VO}_{2}$ kinetic response is fitted with a mono-exponential model of the form (equation 2):

$$
\mathrm{VO}_{2 \mathrm{p}}(\mathrm{t})=\mathrm{VO}_{2 \mathrm{BSLN}}+\operatorname{Amp}\left[1-\mathrm{e}^{-(\mathrm{t}-\mathrm{TD}) / \tau}\right] \quad \text { Equation } 2
$$


where $\mathrm{VO}_{2 \mathrm{p}}$ is $\mathrm{VO}_{2}$ at any time (t); $\mathrm{VO}_{2 \mathrm{BSLN}}$ is baseline $\mathrm{VO}_{2}$; Amp is the steady-state increase in $\mathrm{VO}_{2}$ above baseline; TD is the time delay; and $\tau$ is the phase II $\mathrm{VO}_{2}$ time constant.

\section{Factors Limiting Oxygen Uptake Kinetics}

In order to prevent a fall in intra-cellular [ATP], the rate at which ATP is utilized must be met by the rate of ATP production. Since sustained exercise is greatly dependent on $\mathrm{O}_{2}$ uptake, oxidative phosphorylation is relied upon heavily to produce the necessarily rate of ATP production. The overall reaction describing oxidative phosphorylation can be summarized by equation 3:

$$
\mathrm{NADH}+\mathrm{H}^{+}+1 / 2 \mathrm{O}_{2}+3 \mathrm{ADP}+3 \mathrm{P}_{\mathrm{i}} \rightarrow 3 \mathrm{ATP}+\mathrm{NAD}^{+}+\mathrm{H}_{2} \mathrm{O} \quad \text { Equation } 3
$$

During exercise, if any of the substrates required for oxidative phosphorylation (NADH, $\mathrm{O}_{2}$, and ADP) are not readily available, then the rate of activation of oxidative phosphorylation may be limited and as a result $\mathrm{VO}_{2}$ kinetics could be slowed. Grassi et al. (2011) have shown that $\mathrm{VO}_{2}$ kinetics are tightly regulated/controlled by mechanisms linked to increased [ADP] and the $\mathrm{PCr}$ shuttle system; briefly, PCr breakdown appears to delay or attenuate the increase in [ADP], thereby reducing a more rapid activation of oxidative phosphorylation. To show this they used creatine kinase inhibitors (in canines) to reduce PCr breakdown and increase [ADP] more rapidly, which resulted in faster $\mathrm{VO}_{2}$ kinetics (Grassi et al., 2011). Nevertheless, beyond the basic mechanisms that regulate the rate of increase in oxidative phosphorylation at the exercising muscle, the other determinants of the $\mathrm{VO}_{2}$ kinetic profile are based on a combination of physiological factors; phase II $\mathrm{VO}_{2}$ kinetics are mainly limited by (1) $\mathrm{O}_{2}$ delivery to and within the exercising muscle, and (2) an intracellular control on "metabolic inertia"/'sluggish' activation of enzymes and provision of substrates for oxidative phosphorylation.

\section{(1) Oxygen Delivery}

Studies investigating the effect of $\mathrm{O}_{2}$ delivery on $\mathrm{VO}_{2}$ kinetics have designed experiments that impair $\mathrm{O}_{2}$ transport by varying methods. Beta-adrenergic receptor blockade slowed $\mathrm{VO}_{2}$ kinetics in MOD by reducing heart rate and subsequently $\mathrm{O}_{2}$ transport (Hughson, 1984). Several research groups have also slowed $\mathrm{VO}_{2}$ kinetics with hypoxia (lower fraction of inspired $\mathrm{O}_{2}$ $\left(\mathrm{FiO}_{2}\right)$ and thus reducing arterial partial pressure of oxygen $\left.\left(\mathrm{PaO}_{2}\right)\right)$ across varying work rates (DeLorey et al., 2004c; Hughson \& Kowalchuk, 1995; Spencer et al., 2012; Springer et al., 1991). A change in body position also produces a change in $\mathrm{O}_{2}$ delivery (Hughson et al., 1993; 
MacDonald et al., 1998); slower kinetics are a result of exercising in the supine position (most likely due to reduced perfusion pressure), whereas in the upright position gravity increases driving pressure for arterial blood to perfuse into the working leg muscles (MacDonald et al., 1998). Furthermore, combining interventions that augment both convective $\mathrm{O}_{2}$ delivery and metabolic substrate provision via heavy priming exercise (i.e. MOD1-HVY-MOD2 protocol) but with the addition of hypoxia (through reduced $\mathrm{FiO}_{2}$ which presumably maintains $\mathrm{O}_{2}$ delivery (as an increase in blood flow compensation) but impairs $\mathrm{PaO}_{2}$ and the vascular muscle $\mathrm{O}_{2}$ flux gradient) have resulted in lengthened $\tau \mathrm{VO}_{2}$ despite the priming effects of increase metabolic substrate provision (Spencer et al., 2012). These results suggest that $\mathrm{O}_{2}$ delivery is a major factor in the limitation of the rate of oxidative phosphorylation.

However, when attempting to speed $\mathrm{VO}_{2}$ kinetics via increased $\mathrm{O}_{2}$ availability, especially in the MOD, there seems to be no impact on $\tau \mathrm{VO}_{2}$. In the pump-perfused dog hindlimb model, Grassi and colleagues showed no speeding of $\mathrm{VO}_{2}$ kinetics despite improving bulk convective blood flow and peripheral diffusive $\mathrm{O}_{2}$ delivery (Grassi et al., 1998); although, it needs to be considered that dog gastrocnemius muscle is highly oxidative (more than in humans) and differs in capillarization and blood flow distribution (Grassi et al., 1998). Studies examining the effects of hyperoxia $\left(\mathrm{FiO}_{2}>50 \%\right)$ on $\mathrm{VO}_{2}$ kinetics in MOD found slightly but not significantly faster kinetics in one study (MacDonald et al., 1997), and no effect in others (Bell et al., 1999; Hughson \& Kowalchuk, 1995). However, these results should be considered with caution as hyperoxia also causes systemic vasoconstriction, which will result in reducing blood flow to maintain total $\mathrm{O}_{2}$ delivery (MacDonald et al., 1997).

Recent studies conducted in our laboratory (DeLorey et al., 2004a,b,c, 2007; Murias et al., 2010, 2011a,b, 2012; Spencer et al., 2011, 2012) have used near-infrared spectroscopy (NIRS) to measure tissue oxygenation at the exercising limb (i.e. microvascular $\mathrm{O}_{2}$ delivery); the general conclusion is that (for individuals with $\tau \mathrm{VO}_{2 \mathrm{p}}>\sim 20 \mathrm{~s}$ ) the rate of adjustment of $\mathrm{VO}_{2}$ is

mainly constrained by the matching of local $\mathrm{O}_{2}$ distribution to the muscle (Murias et al., 2011b). Refer to next section for full description of NIRS.

\section{Near-Infared Spectroscopy}

The use of NIRS has generated a method to effectively measure tissue oxygenation via non-invasive observation of microvascular hemoglobin/myoglobin. Infra-red light is used to measure the presence of oxygenated hemoglobin $\left[\mathrm{HbO}_{2}\right]$ and deoxygenated hemoglobin $[\mathrm{HHb}]$ 
within the tissue. Thus, the quantification of specific changes in $\left[\mathrm{HbO}_{2}\right]$ and $[\mathrm{HHb}]$ can be utilized to provide an index of $\mathrm{O}_{2}$ extraction during transitions from baseline to MOD. Therefore, the NIRS method provides an insight into the local microvascular $\mathrm{O}_{2}$ delivery at the working muscle and the rate of $\mathrm{O}_{2}$ utilization.

\section{(2) Substrate Utilization}

Following a step-increase in work rate, there must be an increase in the provision of electrons and reducing equivalents (i.e. $\mathrm{NADH}, \mathrm{FADH}_{2}$ ) to the mitochondrial electron transport chain (ETC), in order for oxidative phosphorylation to increase. For the concentration of NADH to rise there must be an increase in either the breakdown of fat (via $\beta$-oxidation) or the production of pyruvate (from glycolytic pathways). Increases in pyruvate consequently requires increases in the tightly regulated pyruvate dehydrogenase (PDH) production of acetyl-CoA and flux through the tricarboxylic acid cycle (TCA cycle). The hypothesis that a sluggish activation of substrate utilization causes a slowing of $\mathrm{VO}_{2}$ kinetics would suggest that if augmenting $\mathrm{O}_{2}$ delivery causes no perceptible changes in $\tau \mathrm{VO}_{2}$, then the limitation must lie within the metabolic pathways. Pyruvate dehydrogenase has been studied as a potential site of regulation for oxidative phosphorylation (Bangsbo et al., 2002; Grassi et al., 2002; Howlett et al., 1999; Jones et al., 2004; Rossiter et al., 2003); the mitochondrial PDH complex is responsible for regulating the entry of carbohydrate-derived substrate into the TCA cycle and the provision of reducing equivalents to the ETC. Conflicting evidence exists in the literature in both human and canine models. By increasing the activation of PDH via a pharmacological intervention (dichloroacetate: DCA) or heavy-priming exercise there was a significant decrease of the contribution of substrate-level phosphorylation during MOD (Gurd et al., 2006; Howlett et al., 1999). These findings would suggest that the reduction of substrate-level phosphorylation would stem from a more rapid activation of both oxidative phosphorylation and muscle $\mathrm{O}_{2}$ utilization. However, experiments in humans (Bangsbo et al., 2002; Jones et al., 2004; Rossiter et al., 2003) failed to demonstrate faster $\mathrm{VO}_{2}$ kinetics following prior $\mathrm{PDH}$ activation by DCA supplementation. Furthermore, Grassi et al. (2002) used an isolated dog gastrocnemius muscle to show that despite an improved metabolic efficiency (i.e. PCr sparing), there were no effects on $\tau \mathrm{VO}_{2}$. This lack of consensus suggests that the hypothesis of sluggish activation of substrate could result in slow $\mathrm{VO}_{2}$ kinetics, however $\mathrm{O}_{2}$ delivery appears to be a primary factor related to a slow $\mathrm{VO}_{2}$ kinetic response. 
$\mathrm{VO}_{2}$ Kinetics and Aging

The literature shows an age-related slowing of $\mathrm{VO}_{2}$ kinetics $(\sim 7$ s/decade (Babcock et al., 1992)) and consistently slowed $\mathrm{VO}_{2}$ kinetics in older compared to young groups (Babcock et

al., 1994b; Bell et al., 1999; Chilibeck et al., 1996; Cunningham et al., 1993; Murias et al., 2010). Unlike other studies on younger subjects that indicate a control and limit of $\mathrm{VO}_{2}$ kinetics in the rate of muscle oxidative metabolism (via oxygen delivery and substrate utilization) (Grassi et al., 1996), the slower $\mathrm{VO}_{2}$ kinetics in older adults most likely reflects a limitation in $\mathrm{O}_{2}$ delivery to the exercising muscle (Chilibeck et al., 1996; Murias et al., 2010). This reduced ability to deliver $\mathrm{O}_{2}$ to the muscle with aging is most likely partially due to the paralleled slower heart rate kinetics in older adults (Cunningham et al., 1993). Additionally, researchers in our laboratory (DeLorey et al., 2004a; Murias et al., 2010) have shown an age-related reduction in microvascular blood flow (reflected by a greater ratio of change in deoxygenated hemoglobin to change in $\mathrm{VO}_{2 \mathrm{p}}$ ) in older men; thus, older adults rely more on $\mathrm{O}_{2}$ extraction during transition to MOD, probably due to lower microvascular blood flow. Furthermore, Musch et al. (2004) studying aged rats found a redistribution of muscle blood flow during submaximal exercise in older compared to young, which could contribute to reduced $\mathrm{O}_{2}$ delivery. Therefore, evidence suggests that a potential deterioration of microvascular $\mathrm{O}_{2}$ delivery exists in the aging human population. Recently, Murias and colleagues revealed that mechanisms exist, other than bulk blood flow (Q), which could limit aerobic function (Murias et al., 2010); thus, it is important to examine both $\mathrm{VO}_{2}$ max and $\mathrm{VO}_{2}$ kinetics in order to characterize the change in aerobic function in aging populations.

\subsection{AEROBIC FUNCTION AND AGING IN ENDURANCE TRAINED}

\subsubsection{Maximal Aerobic Power}

The above section outlines the effects of aging on regular healthy individuals. It is of interest to examine what effects endurance training has on the aging population. Numerous studies have showed that endurance-trained men have higher $\mathrm{VO}_{2}$ max values than age-matched untrained men (Fuchi et al., 1989; Hagberg et al., 1985; Pimental et al., 2003; Rogers et al., 1990; Trappe et al., 1996; Wilson \& Tanaka, 2000). As outlined above (refer to section 1.2.1), regular healthy men experience a natural decline in $\mathrm{VO}_{2} \max$ at a rate of $\sim 10$ to $15 \%$ per decade (Paterson \& Cunningham, 1999; Paterson et al., 1999; Rogers et al., 1990; Stathokostas et al., 2004; Trappe et al., 1996); whereas, endurance-trained men appear to attenuate ( 6 to $10 \%$ per 
decade) the expected age-related decline in relative $\mathrm{VO}_{2} \max$ (Fuchi et al., 1989; Hagberg et al., 1985; Pimental et al., 2003; Rogers et al., 1990; Trappe et al., 1996; Wilson \& Tanaka, 2000). The reduction in $\mathrm{VO}_{2} \mathrm{max}$ in healthy men can be attributed to a reduction in Q (Fuchi et al., 1989; Pimental et al., 2003), which is partially attributed to the natural decline in maximal HR. Other researchers have found that the decline in both maximal $\mathrm{HR}$ and $\mathrm{a}-\mathrm{vO}_{2}$ difference contribute to the reduced $\mathrm{VO}_{2}$ max with age (Beere et al., 1999; Hagberg et al., 1985; Rogers et al., 1990; Trappe et al., 1996). Older endurance trained men lessened the reduction in the $\mathrm{VO}_{2}$ max by attenuation of the decline in $\mathrm{Q}$ (via elevated stroke volume to compensate for the decline in maximal $\mathrm{HR}$ ) and a- $\mathrm{vO}_{2}$ difference (Hagberg et al., 1985), compared to their healthy counterparts. The endurance-trained do show a reduction in maximal HR with age (Fuchi et al., 1989; Hagberg et al., 1985; Trappe et al., 1996), but also the degree of loss in $\mathrm{VO}_{2}$ max has been attributed to the reduction in training intensity or volume (Pimental et al., 2003; Rogers et al., 1990).

Interestingly, the above-mentioned studies tested chronically endurance-trained men, however other researchers (Beere et al., 1999; Murias et al., 2011a) have seen similar adaptations from only 3 to 6 months of endurance training in regular healthy older men. Murias et al. (2011a) found increased capillarization (reflecting improved $\mathrm{O}_{2}$ delivery) and citrate synthase activity following 12 weeks of endurance training; these results suggest there is a potential for an increased capacity of $\mathrm{O}_{2}$ to be utilized and distributed within the active muscle. These studies have shown that regular healthy older men could increase $\mathrm{VO}_{2} \mathrm{max}$ from endurance training by increasing a- $\mathrm{vO}_{2}$ difference (Beere et al., 1999) or both a- $\mathrm{vO}_{2}$ difference and $\mathrm{Q}$ (with improvements in Q representing approximately 2/3 of the difference) (Murias et al., 2011a). Therefore, endurance training can attenuate (or slightly reverse) the effects of aging by retaining a greater capacity for $\mathrm{O}_{2}$ delivery and $\mathrm{O}_{2}$ utilization with chronic endurance training (or following a 3 to 6 month bout of endurance training).

\subsection{2 $\mathrm{VO}_{2}$ Kinetics}

Endurance exercise training has been shown to result in a speeding of $\mathrm{VO}_{2}$ kinetics following the onset of moderate intensity exercise both in young (Fukuoka et al., 2002; Koppo et al., 2004; Murias et al., 2010) and older men (Babcock et al., 1994a; Bell et al., 2001a; Berger et al., 2006a; Fukuoka et al., 2002; Murias et al., 2010), and older women (Dogra et al., 2013). Endurance training in the elderly has shown substantial $(38-48 \%)$ reductions in $\tau \mathrm{VO}_{2}$ such that 
values approach those found in younger subjects (Babcock et al., 1994a; Bell et al., 2001a; Fukuoka et al., 2002; Murias et al., 2010). This speeding (especially in older adults) is likely a result of physiological adaptations that improve muscle $\mathrm{O}_{2}$ availability (i.e., enhanced muscle perfusion or blood flow) (Murias et al., 2010). These data also suggest that the slowing of $\mathrm{VO}_{2}$ kinetics in older individuals is related, to a large extent, to a reduction in physical activity and/or aerobic fitness with age (Berger et al., 2006a). DeSouza et al. (2000) found that middle-aged and older endurance-trained men were able to reverse the age-related loss in endothelium-dependent vasodilation to that of younger endurance-trained men. This maintained endothelium vasodilatory response could possibly provide a mechanism by which improved $\mathrm{O}_{2}$ delivery (via $\mathrm{O}_{2}$ diffusion at the capillaries) in endurance-trained men could speed $\mathrm{VO}_{2}$ kinetics.

Interestingly, the amount by which the slowing of $\mathrm{VO}_{2}$ kinetics can be attenuated is dependent upon the type of training; Berger et al. (2006a) examined both endurance- and sprinttrained athletes from ages 46 to 85 and found that endurance trained athletes maintained similar $\tau \mathrm{VO}_{2}$ values to that of healthy younger individuals, whereas sprint trained athletes had a slowing of $\mathrm{VO}_{2}$ kinetics with age (however all $\tau \mathrm{VO}_{2}$ values in the sprint group were still below the agematched sedentary counterparts). Additionally, just one bout of heavy-priming exercise will speed $\mathrm{VO}_{2}$ kinetics in both young (Spencer et al., 2012) and older men (DeLorey et al., 2004b; Scheuermann et al., 2002), presumably as a result of improved $\mathrm{O}_{2}$ delivery (Scheuermann et al., 2002).

Although it is well known that $\mathrm{VO}_{2}$ max is lower and $\tau \mathrm{VO}_{2 \mathrm{p}}$ is greater in older compared to young individuals, little data exists on middle-aged men. It has also been shown that endurance training will increase $\mathrm{VO}_{2} \max$ (Beere et al., 1999; Hagberg et al., 1985; Pimental et al., 2003; Rogers et al., 1990; Trappe et al., 1996) and lower $\tau \mathrm{VO}_{2 p}$ (Berger et al., 2006a; DeSouza et al., 2000; McKay et al., 2009; Murias et al., 2010) in young and older individuals. Therefore, the purpose of the study herein was to examine the $\mathrm{VO}_{2}$ responses in young, middleaged, and older, endurance trained and untrained men. It was hypothesized that there would be a continuous increase in $\tau \mathrm{VO}_{2 \mathrm{p}}$ from young to older men, in both the trained and untrained groups, with $\tau \mathrm{VO}_{2 \mathrm{p}}$ values in the trained groups lower than the untrained counterparts. Additionally, it was hypothesized that the $[\mathrm{HHb}]$ in groups with slow $\mathrm{VO}_{2}$ kinetics would reveal a greater muscle deoxygenation for a given $\mathrm{VO}_{2}$ during the exercise transient, representing a sluggish microvascular $\mathrm{O}_{2}$ delivery. 


\section{CHAPTER 2}

\section{THE EFFECTS OF AGE AND LONG-TERM ENDURANCE TRAINING ON VO KINETICS}

\subsection{INTRODUCTION}

Studies of the physiological response to exercise in different age groups, particularly young and older, have been conducted to infer that age-related changes exist (Jackson et al., 1995; Murias et al., 2010; Wilson \& Tanaka, 2000). Additionally, comparisons of highly trained versus more sedentary groups of different ages have allowed the assessment as to whether agerelated changes may be in part due to lack of physical activity or whether long-term physical activity prevents or reduces these losses. In particular, many studies have examined the agerelated changes in $\mathrm{VO}_{2}$ max in highly trained and untrained individuals (Jackson et al., 1995; Pimental et al., 2003; Stathokostas et al., 2004; Wilson \& Tanaka, 2000). However, for the

aerobic parameter of $\mathrm{VO}_{2}$ kinetics, few studies have examined the differences across age groups and particularly in chronically trained and untrained men in different age groups.

The $\mathrm{VO}_{2}$ kinetic profile during the transition to moderate-intensity exercise is slower in older individuals compared to young healthy men (Babcock et al., 1992, 1994b; Murias et al., 2010); thus, older individuals display a larger $\mathrm{O}_{2}$ deficit and may experience premature fatigue (DeLorey et al., 2007). The slower $\mathrm{VO}_{2}$ kinetics associated with aging may be associated with a limitation in $\mathrm{O}_{2}$ delivery to the exercising muscle (Murias et al., 2010). Endurance training exercise has been shown to speed $\mathrm{VO}_{2}$ kinetics in young (Koppo et al., 2004; Murias et al., 2010), middle-aged (Berger et al., 2006a; Fukuoka et al., 2002), and older (Babcock et al., 1994a; Bell et al., 2001a; Berger et al., 2006a; Murias et al., 2010) men. However, it remains unclear whether the age-related slowing of $\mathrm{VO}_{2}$ kinetics is due to aging per se or a lack of physical activity. Since $\mathrm{VO}_{2}$ kinetics is a measure of differing physiological regulations/control of aerobic metabolism, analysis of $\mathrm{VO}_{2}$ kinetics will shed further light on changes with age and the influence of differing levels of physical activity.

A number of studies have examined the time course adjustment of $\mathrm{VO}_{2 p}$ during the transitions to moderate-intensity exercise in young and older men (Chilibeck et al., 1997; DeLorey et al., 2004a, 2007; Gurd et al., 2008; Murias et al., 2010); however, there has been 
limited study of the $\mathrm{VO}_{2 \mathrm{p}}$ kinetics of middle-aged and older men (Berger et al., 2006a; Fukuoka et al., 2002). Thus, the main goal of this study was to examine the age-related differences in $\mathrm{VO}_{2}$ kinetics of untrained young, middle-aged and older groups of men, and to compare to agematched groups of endurance trained men. Additionally, the goal was to determine if the same mechanism responsible for slower $\mathrm{VO}_{2}$ kinetics in older men (i.e. an $\mathrm{O}_{2}$ delivery limitation) (Murias et al., 2010) exists in other groups with slow $\mathrm{VO}_{2}$ kinetics. We hypothesized that there would be a continuous increase in the phase II $\mathrm{VO}_{2 \mathrm{p}}$ time constant $\left(\tau \mathrm{VO}_{2 \mathrm{p}}\right)$ from young to middle-aged to older men, in both the trained and untrained groups, with $\tau \mathrm{VO}_{2 \mathrm{p}}$ values in the trained groups always lower than the untrained counterparts; thus, the slowed $\mathrm{VO}_{2}$ kinetics with age would not be largely attenuated in endurance trained. It was further hypothesized that in groups with slower $\mathrm{VO}_{2}$ kinetics there would be an associated rapid rate of muscle deoxygenation suggesting an $\mathrm{O}_{2}$ delivery limitation at the microvascular/active muscle level.

\subsection{METHODS}

Participants: 36 healthy men volunteered and gave written consent to participate in this study. Additionally the data of 15 healthy men from studies completed previously ( $\leq 3$ years prior) in the lab using similar equipment and protocol were retrieved. Subjects were separated into three groups: young (18 - $35 \mathrm{yr})$, middle-aged (40 - $59 \mathrm{yr})$, and older (60 - $85 \mathrm{yr})$. Each group was further separated into two categories, trained and untrained, yielding six groups: young trained (YT) and untrained (YuT), middle-aged trained (MT) and untrained (MuT), and older trained (OT) and untrained (OuT). All procedures were approved by The University of Western Ontario Research Ethics Board for Health Sciences Research Involving Human Subjects. All participants were non-smokers and were not taking medications that would affect the cardiorespiratory or hemodynamic responses to exercise.

Subject Training Status: The untrained (recreationally active) men were not actively training or participating in an exercise training program, and were recruited by publically-posted flyers. The endurance trained men were competitive and/or actively training cyclists and were recruited by flyers posted at their cycling clubs. All trained cyclists had been training for $\geq 5$ years in YT and $\geq 10$ years in MT and OT, and typically cycled at least 5 times/wk for $>300 \mathrm{~km} \bullet \mathrm{wk}^{-1}$. 
Protocol: On day one, participants reported to the laboratory to perform a ramp incremental test $\left(30 \mathrm{~W} \cdot \mathrm{min}^{-1}\right.$ for YT and MT, $25 \mathrm{~W} \bullet \mathrm{min}^{-1}$ for YuT, MuT, and OT, and $20 \mathrm{~W} \bullet \mathrm{min}^{-1}$ for OuT) to the limit of tolerance on a cycle ergometer (model: H-300-R Lode; Lode B.V., Groningen, Holland) for determination of maximal $\mathrm{VO}_{2}\left(\mathrm{VO}_{2} \max \right)$ and the estimated lactate threshold $\left(\theta_{\mathrm{L}}\right)$; the ramp portion of the protocol was initiated following 4 minutes of cycling at $20 \mathrm{~W}$ (watts). Peak $\mathrm{VO}_{2}\left(\mathrm{VO}_{2} \max \right)$ was determined as the maximal $20 \mathrm{~s}$ averaged $\mathrm{VO}_{2 \mathrm{p}}$ value during the last 60 s of the ramp incremental test. The maximal HR and RER (respiratory exchange ration) values during the ramp incremental test were obtained by averaging the final 30 seconds of the trial. $\theta_{\mathrm{L}}$ was determined by visual inspection as the $\mathrm{VO}_{2}$ at which $\mathrm{CO}_{2}$ (carbon dioxide) output $\left(\mathrm{VCO}_{2}\right)$ began to increase out of proportion in relation to $\mathrm{VO}_{2}$, with a systematic rise in minute ventilation-to- $\mathrm{VO}_{2}$ ratio and end-tidal $\mathrm{PO}_{2}$ (partial pressure of $\mathrm{O}_{2}$ ) whereas minute ventilation-to$\mathrm{VCO}_{2}$ ratio and end-tidal $\mathrm{PCO}_{2}$ (partial pressure of $\mathrm{CO}_{2}$ ) were stable (Beaver et al., 1986).

From the results of this ramp test, a moderate-intensity work rate (WR) was selected to elicit a $\mathrm{VO}_{2}$ equivalent to $\sim 80 \%$ of the $\mathrm{VO}_{2}$ at $\theta_{\mathrm{L}}$ (MOD). On a second laboratory session, subjects completed three continuous transitions from cycling at baseline $(20 \mathrm{~W})$ to cycling at MOD, each for 6 minutes. The cycling transitions between baseline and MOD were initiated as a "step" change. Subjects were instructed to maintain a pedal rate between 60 - 70 RPM throughout the trial.

Measurements: Gas exchange measurements were similar to those previously described (Babcock et al., 1994b). Briefly, inspired and expired flow rates were measured using a low dead space (90 mL) bidirectional turbine (Alpha Technologies VMM 110), which was calibrated before each test using a syringe of known volume. Inspired and expired gases were continuously sampled $(50 \mathrm{~Hz})$ at the mouth and analyzed for concentrations of $\mathrm{O}_{2}, \mathrm{CO}_{2}$, and $\mathrm{N}_{2}$ by mass spectrometry (Innovision, AMIS 2000, Lindvedvej, Denmark) after calibration with precisionanalyzed gas mixtures. Changes in gas concentrations were aligned with gas volumes by measuring the time delay for a square-wave bolus of gas passing the turbine to the resulting changes in fractional gas concentrations as measured by the mass spectrometer. Data were transferred to a computer, which aligned concentrations with volume information to build a profile of each breath. Breath-by-breath alveolar gas exchange was calculated by using algorithms of Beaver et al. (1981).

HR was monitored continuously by electrocardiogram (three-lead arrangement) using 
PowerLab (ML132/ML880; ADInstruments, Colorado Springs, CO). Data were recorded using LabChart v6.1 (ADInstruments, Colorado Springs, CO) on a separate computer.

Local muscle deoxygenation $([\mathrm{HHb}])$ of the quadriceps vastus lateralis muscle was monitored continuously with a frequency-domain multi-distance NIRS system (Oxiplex TS, Model 95205, ISS, Champaign, IL, USA) as previously described by Murias et al. (2012). Briefly, the arrangement for the present study included a single channel consisting of eight laser diodes operating at two wavelengths $(\lambda=690$ and $828 \mathrm{~nm}$, four at each wavelength) which were pulsed in a rapid succession, and a photomultiplier tube. The lightweight plastic NIRS probe (connected to laser diodes and photomultiplier tube by optical fibers) consisted of two parallel rows of light emitter fibers and one detector fiber bundle; the source-detector separations for this probe were 2.0, 2.5, 3.0, and $3.5 \mathrm{~cm}$ for both wavelengths. The probe was placed on the belly of the muscle midway between the lateral epicondyle and greater trochanter of the femur; it was covered with an optically-dense, black vinyl sheet, thus minimizing the intrusion of extraneous light and secured in place with an elastic strap tightened to prevent movement of the probe. NIRS measurements were collected continuously for the entire duration of each trial. This allowed for continuous measurement of absolute concentration changes of oxyhemoglobin $\left(\left[\mathrm{HbO}_{2}\right]\right)$ and $[\mathrm{HHb}]$.

The near-infrared spectrometer was calibrated at the beginning of each testing session following a warm-up period of at least $20 \mathrm{~min}$. The calibration was done with the probe placed on a calibration block (phantom) with absorption $\left(\mu_{\mathrm{A}}\right)$ and reduced scattering coefficients $\left(\mu_{\mathrm{s}}\right.$ ') previously measured; thus, correction factors were determined and were automatically implemented by the manufacturer's software for the calculation of the $\mu_{\mathrm{A}}$ and $\mu_{\mathrm{s}}$ ' for each wavelength during the data collection. Calculation of $[\mathrm{HHb}]$ reflected continuous measurements of $\mu_{\mathrm{s}}$ ' made throughout each testing session (i.e., constant scattering value not assumed). Data were stored online at an output frequency of $25 \mathrm{~Hz}$, but were reduced to $1 \mathrm{~s}$ bins for all subsequent analyses within the present study.

Data analysis: $\mathrm{VO}_{2 \mathrm{p}}$ data were filtered by removing aberrant data points that lay outside 4 standard deviations (SD) of the local mean. Data for each repetition were then linearly interpolated to $1 \mathrm{~s}$ intervals, time-aligned such that time zero represented each transition and ensemble-averaged to yield a single averaged response for each subject. These averaged 
responses were further time-averaged into $5 \mathrm{~s}$ bins. The on-transient responses for $\mathrm{VO}_{2 \mathrm{p}}$ were modelled using the following equation:

$$
\mathrm{Y}_{(t)}=\mathrm{Y}_{\mathrm{BSLN}}+\mathrm{A}\left(1-\mathrm{e}^{-(t-\mathrm{TD}) / \tau}\right) ;[\text { Equation } 1]
$$

where $\mathrm{Y}_{(t)}$ represents the $\mathrm{VO}_{2 \mathrm{p}}$ at any given time $(t)$; $\mathrm{Y}_{\mathrm{BSLN}}$ is the steady state baseline value of $\mathrm{Y}$ before an increase in WR; $\mathrm{A}$ is the amplitude of the increase in $\mathrm{Y}$ above $\mathrm{Y}_{\mathrm{BSLN}}$; $\tau$ represents the time required to attain $63 \%$ of the steady-state amplitude; and TD represents the mathematically generated time delay through which the exponential model is predicted to intersect $\mathrm{Y}_{\mathrm{BSLN}}$. After excluding the initial $20 \mathrm{~s}$ of data from the model, while still allowing TD to vary freely (in order to optimize accuracy of parameter estimates), $\mathrm{VO}_{2 \mathrm{p}}$ data were modeled to 4 min $(240 \mathrm{~s})$ of the step-transition; this ensured that each subject had attained a $\mathrm{VO}_{2 p}$ steady-state, yet did not bias the model fit during the on-transient (Bell et al., 2001b). The model parameters were estimated by least-squares nonlinear regression (Origin, OriginLab Corp., Northampton, MA, USA) in which the best fit was defined by minimization of the residual sum of squares and minimal variation of residuals around the $\mathrm{Y}$-axis $(\mathrm{Y}=0)$. The $95 \%$ confidence interval for the estimated time constant was determined after preliminary fit of the data with $\mathrm{Y}_{\mathrm{BSLN}}$, A, and TD constrained to the best-fit values and the $\tau$ allowed to vary.

The $[\mathrm{HHb}]$ profile has been described to consist of a time delay at the onset of exercise, followed by an increase in the signal with an "exponential-like" time-course. The time delay for the $[\mathrm{HHb}]$ response $(\mathrm{TD}[\mathrm{HHb}])$ was determined using second-by-second data and corresponded to the time, after the onset of exercise, at which the $[\mathrm{HHb}]$ signal began a systematic increase from its nadir value. Determination of the TD $[\mathrm{HHb}]$ was made on individual trials and averaged to yield specific values for each individual. The $[\mathrm{HHb}]$ data were modeled using Equation 1; the fitting window for the "exponential" response spanned from the end of the TD[HHb] to $90 \mathrm{~s}$ into each transition. As described previously (duManoir et al., 2010), different fitting strategies ranging from 90-180 s into a transition resulted in minimal differences in estimates of $\tau[\mathrm{HHb}$. Baseline $[\mathrm{HHb}]\left([\mathrm{HHb}]_{\mathrm{BSLN}}\right)$ values were computed as the mean value in the $60 \mathrm{~s}$ prior to a transition. Whereas the $\tau[\mathrm{HHb}]$ described the time course for the increase in $[\mathrm{HHb}]$, the overall change of the effective $[\mathrm{HHb}]\left(\tau^{\prime}[\mathrm{HHb}]=\mathrm{TD}[\mathrm{HHb}]+\tau[\mathrm{HHb}]\right)$ described the overall time course of the $[\mathrm{HHb}]$ from the onset of the step transition.

Calculations of the $[\mathrm{HHb}] / \mathrm{VO}_{2 \mathrm{p}}$ ratio were similar to those previously described (Murias 
et al., 2011b, 2012). Briefly, the second-by-second [HHb] and $\mathrm{VO}_{2 \mathrm{p}}$ data were normalized for each subject ( $0 \%$ representing the $20 \mathrm{~W}$ baseline value, and $100 \%$ representing the posttransition steady-state). This normalization procedure was undertaken so that the specific time course of adjustment in the respective signals could be considered without concern for signal amplitude. The normalized $\mathrm{VO}_{2 \mathrm{p}}$ was left-shifted $20 \mathrm{~s}$ to account for the phase I-Phase II transition, so that the onset of exercise coincided with the beginning of phase II $\mathrm{VO}_{2 \mathrm{p}}$ (Murias et al., 2011b), which has been previously described to correspond with muscle $\mathrm{VO}_{2}\left(\mathrm{VO}_{2 \mathrm{~m}}\right)$ within 10\% (Grassi et al., 1996). Data were further averaged into 5-s bins for statistical comparison of the rate of adjustment for $[\mathrm{HHb}]$ and $\mathrm{VO}_{2 \mathrm{p}}$. Additionally, an overall average $[\mathrm{HHb}] / \mathrm{VO}_{2 \mathrm{p}}$ ratio for the adjustment period during the exercise on-transient was derived for each individual as the average of the twenty-one $5 \mathrm{~s}$ ratio values from 20 to $120 \mathrm{~s}$ (approximating the start of the $[\mathrm{HHb}] / \mathrm{VO}_{2 \mathrm{p}}$ "overshoot" to the time point at which the ratio reached the steady-state value of 1.0 in all groups). The limitations of this analysis are detailed in Murias et al. (2011b).

Statistics: Data are presented as means \pm SD. Two-way analysis of variance (ANOVA) was used to determine statistical significance for the dependent variables. Tukey post-hoc tests were used when significant differences were found for the main effects and to quantify the strength of relationships between variables. All statistical analyses were performed using SPSS Version 18.0, (SPSS Inc., Chicago, IL). Statistical significance was declared when $\mathrm{P}<0.05$.

\subsection{RESULTS}

Subject characteristics and peak exercise values are listed in Table 1. Subjects reached volitional fatigue during the ramp incremental test with the mean HR data at, or no less than 5 beats $\bullet \min ^{-1}$ below, the age-predicted maximum and mean RER data greater than 1.2 for all groups. The training program data of each of the endurance-trained groups are listed in Table 2. The endurance-trained men reported cycling for 435, 309, and $304 \mathrm{~km} \bullet \mathrm{wk}^{-1}$ in the YT, MT, and OT groups, respectively. The trained cyclists were also long-term endurance athletes and had been training for 6, 15, and 23 years prior to testing in the YT, MT, and OT groups, respectively.

Individual $\mathrm{VO}_{2}$ max data, as well as group means and $\mathrm{SD}$, are presented in Fig. 1. $\mathrm{VO}_{2}$ max significantly $(\mathrm{P}<0.05)$ decreased with age in both trained $(66.0 \pm 7.6,55.3 \pm 7.3$, and $45.5 \pm 9.0 \mathrm{~mL} \cdot \mathrm{kg}^{-1} \bullet \mathrm{min}^{-1}$, for YT, MT, and OT, respectively) and untrained (49.9 $\pm 3.7,45.3 \pm$ 
7.9, and $29.0 \pm 5.3 \mathrm{~mL} \cdot \mathrm{kg}^{-1} \bullet \mathrm{min}^{-1}$, for YuT, MuT, and OuT, respectively) groups. $\mathrm{VO}_{2}$ max was significantly $(\mathrm{P}<0.05)$ greater in each trained group compared to the corresponding agematched untrained group. The estimated lactate thresholds were: $2.8 \pm 0.5,2.4 \pm 0.3$, and $2.1 \pm$ $0.2 \mathrm{~L} \bullet \mathrm{min}^{-1}$ for the trained groups (YT, MT, and OT, respectively) and 2.2 $\pm 0.3,2.2 \pm 0.2$, and $1.6 \pm 0.3 \mathrm{~L} \cdot \mathrm{min}^{-1}$ for the untrained groups (YuT, MuT, and OuT, respectively).

$\mathrm{VO}_{2}$ Kinetics. Individual $\tau \mathrm{VO}_{2 \mathrm{p}}$ data, as well as group means and $\mathrm{SD}$, are presented in Fig. 2. Phase II $\tau \mathrm{VO}_{2 \mathrm{p}}$ was similar between the trained and untrained groups for both $\mathrm{Y}$ and $\mathrm{M}$ groups (Table 3). $\tau \mathrm{VO}_{2 \mathrm{p}}$ did not significantly increase with age in the trained group; whereas, $\tau \mathrm{VO}_{2 \mathrm{p}}$ was not different between YuT and MuT but it was greater $(\mathrm{P}<0.05)$ in the OuT compared to YuT, MuT, and OT (Table 3). Based on the assigned MOD work rates, $\mathrm{VO}_{2 \mathrm{p}}$ AMP significantly $(\mathrm{P}<0.05)$ decreased with age in both trained and untrained groups, and was greater $(\mathrm{P}<0.05)$ in each trained group compared to the corresponding age-matched untrained group (Table 3). $\mathrm{VO}_{2 \mathrm{p}} \mathrm{TD}$ was significantly $(\mathrm{P}<0.05)$ lower in the untrained compared to trained groups (for $\mathrm{Y}$ and $\mathrm{O}$ ).

[HHb] Kinetics. $\tau[\mathrm{HHb}]$ as well as the overall time course of [HHb], reflected as $\tau^{\prime}$ $[\mathrm{HHb}]$, were longer $(\mathrm{P}<0.05)$ in the untrained compared to the trained groups (for $\mathrm{M}$ and $\mathrm{O}$; Table 4$)$. The TD $[\mathrm{HHb}]$ was longer $(\mathrm{P}<0.05)$ in the OT compared to the YT.

The normalized $(\%)$ responses of $[\mathrm{HHb}]$ and $\mathrm{VO}_{2 \mathrm{p}}$ adjustments to the step-transition in work rate are presented in Fig. 3. Greater adjustment in $[\mathrm{HHb}]$ compared to $\mathrm{VO}_{2 \mathrm{p}}$ resulted in a small transient "overshoot" in $[\mathrm{HHb}] / \mathrm{VO}_{2 \mathrm{p}}$ for YuT, MT, OT and a relatively large value in OuT (Fig. 4); however, only the OuT overshoot was significantly greater when compared across age and against the trained counterpart. Furthermore, the overshoot in the YuT, MT and OT groups was relatively short (from 25 to $\leq 35 \mathrm{~s}$ ), whereas the OuT overshoot extended from 20 to $75 \mathrm{~s}$. 
Table 1: Subject characteristics and peak exercise responses

\begin{tabular}{cccccccc}
\hline & & $\begin{array}{c}\text { Age } \\
(\mathbf{y r})\end{array}$ & $\begin{array}{c}\text { Body Mass } \\
(\mathbf{k g})\end{array}$ & $\begin{array}{c}\text { Height } \\
(\mathbf{c m})\end{array}$ & $\begin{array}{c}\mathbf{V O}_{2} \mathbf{m a x} \\
\left(\mathbf{L}^{\bullet} \mathbf{m i n}^{-\mathbf{1}}\right)\end{array}$ & $\begin{array}{c}\text { HR max } \\
\left(\mathbf{b e a t s}^{\bullet} \mathbf{m i n}^{-\mathbf{1}}\right)\end{array}$ & RER max \\
\hline YT & 8 & $24 \pm 6$ & $68 \pm 9$ & $177 \pm 5$ & $4.5 \pm 0.5$ & $195 \pm 7$ & $1.26 \pm 0.06$ \\
MT & 9 & $52 \pm 5$ & $80 \pm 7$ & $179 \pm 7$ & $4.4 \pm 0.4$ & $176 \pm 5^{\dagger}$ & $1.21 \pm 0.08$ \\
OT & 9 & $64 \pm 3$ & $77 \pm 12$ & $181 \pm 8$ & $3.4 \pm 0.4^{\dagger \dagger}$ & $165 \pm 6^{\dagger \dagger}$ & $1.21 \pm 0.05$ \\
\hline YuT & 8 & $23 \pm 4$ & $80 \pm 9$ & $181 \pm 6$ & $4.0 \pm 0.4$ & $194 \pm 3$ & $1.32 \pm 0.08$ \\
MuT & 9 & $52 \pm 2$ & $80 \pm 9$ & $175 \pm 6$ & $3.6 \pm 0.4^{*}$ & $173 \pm 8^{\dagger}$ & $1.24 \pm 0.06$ \\
OuT & 8 & $68 \pm 5$ & $85 \pm 11$ & $174 \pm 7$ & $2.5 \pm 0.6^{* \dagger}$ & $154 \pm 9^{\dagger \dagger}$ & $1.33 \pm 0.10$ \\
\hline
\end{tabular}

Values are means \pm SD. YT, young trained; MT, middle-aged trained; OT, older trained; YuT, young untrained; MuT, middle-aged untrained; OuT, older untrained; HR, heart rate; RER, respiratory exchange ratio. *, significantly different from age-matched trained group $(\mathrm{P}<0.05)^{\dagger}$, significantly different from training-matched young group $(\mathrm{P}<0.05)$; ${ }^{\ddagger}$, significantly different from training-matched middle group $(\mathrm{P}<0.05)$. 
Table 2: Group average training program data for the endurance-trained men

\begin{tabular}{cccc}
\hline Trained & $\begin{array}{c}\text { \# of rides } \\
\left(\mathbf{w k}^{\mathbf{- 1}}\right)\end{array}$ & $\begin{array}{c}\text { Weekly Distance } \\
\left(\mathbf{k m} \bullet \mathbf{w k}^{-\mathbf{1}}\right)\end{array}$ & $\begin{array}{c}\text { Years Training } \\
(\mathbf{y r})\end{array}$ \\
\hline YT & $6.1 \pm 0.7$ & $435 \pm 180$ & $6.0 \pm 2.9$ \\
MT & $5.0 \pm 0.9$ & $309 \pm 84$ & $15.4 \pm 6.5$ \\
OT & $4.8 \pm 0.4$ & $304 \pm 71$ & $23.0 \pm 6.8$ \\
\hline
\end{tabular}

Values are means \pm SD. YT, young trained; MT, middle-aged trained; OT, older trained. 
Table 3: $\mathrm{VO}_{2 \mathrm{p}}$ kinetic parameters for the transition to moderate-intensity exercise

\begin{tabular}{|c|c|c|c|c|c|}
\hline & 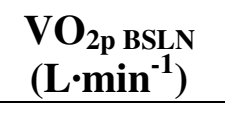 & $\begin{array}{l}\mathrm{VO}_{2 p} \text { AMP } \\
\left(\mathbf{L} \cdot \mathrm{min}^{-1}\right) \\
\end{array}$ & $\begin{array}{c}\mathrm{TD} \mathrm{VO}_{2 p} \\
(\mathrm{~s})\end{array}$ & $\begin{array}{c}\tau \mathrm{VO}_{2 p} \\
(\mathrm{~s})\end{array}$ & $\begin{array}{c}\mathbf{C I}_{95} \\
(\mathbf{s})\end{array}$ \\
\hline YT & $0.98 \pm 0.22$ & $1.32 \pm 0.33$ & $16.1 \pm 1.1$ & $17.0 \pm 7.5$ & $1.9 \pm 0.3$ \\
\hline MT & $1.03 \pm 0.20$ & $1.07 \pm 0.28^{\dagger}$ & $16.1 \pm 3.1$ & $18.1 \pm 5.3$ & $2.7 \pm 0.9$ \\
\hline OT & $0.93 \pm 0.15$ & $0.82 \pm 0.2^{\dagger \ddagger}$ & $15.7 \pm 1.8$ & $19.8 \pm 5.4$ & $3.3 \pm 1.7$ \\
\hline YuT & $1.06 \pm 0.18$ & $1.00 \pm 0.21^{*}$ & $11.2 \pm 5.8^{*}$ & $25.7 \pm 6.6$ & $2.3 \pm 1.0$ \\
\hline MuT & $0.97 \pm 0.13$ & $0.92 \pm 0.22 *^{\dagger}$ & $14.5 \pm 5.3$ & $24.4 \pm 7.4$ & $2.6 \pm 1.2$ \\
\hline OuT & $0.91 \pm 0.12$ & $0.55 \pm 0.21^{* \dagger}$ & $10.2 \pm 8.0 *$ & $42.0 \pm 11.3^{* \dagger}$ & $4.8 \pm 3.0$ \\
\hline
\end{tabular}

Values are means \pm SD. YT, young trained; MT, middle-aged trained; OT, older trained; YuT, young untrained; MuT, middle-aged untrained; OuT, older untrained; $\mathrm{VO}_{2 \mathrm{p}}$, pulmonary $\mathrm{VO}_{2}$; BSLN, baseline; AMP, amplitude; TD, time delay; $\tau$, time constant of response; $\mathrm{CI}_{95}, 95 \%$ confidence interval of $\tau \mathrm{VO}_{2 \mathrm{p}}$. ${ }^{*}$, significantly different from age-matched trained group $(\mathrm{P}<$ $0.05) ;{ }^{\dagger}$, significantly different from training-matched young group $(\mathrm{P}<0.05) ;{ }^{\ddagger}$, significantly different from training-matched middle group $(\mathrm{P}<0.05)$. 
Table 4: $[\mathrm{HHb}]$ kinetic parameters for the transition to moderate-intensity exercise

\begin{tabular}{ccccc}
\hline & TD[HHb] (s) & $\boldsymbol{\tau}[\mathbf{H H b}](\mathbf{s})$ & $\boldsymbol{\tau}^{\prime}[\mathbf{H H b}](\mathbf{s})$ & {$[\mathbf{H H b}] / \mathbf{V O}_{\mathbf{2 p}}$} \\
\hline YT & $9.0 \pm 2.1$ & $10.8 \pm 2.9$ & $19.8 \pm 2.5$ & $1.01 \pm 0.07$ \\
MT & $10.1 \pm 1.8$ & $7.7 \pm 2.0$ & $17.9 \pm 2.6$ & $1.04 \pm 0.05$ \\
OT & $12.3 \pm 3.1^{\dagger}$ & $7.7 \pm 3.0$ & $20.0 \pm 3.5$ & $1.04 \pm 0.04$ \\
\hline YuT & $9.4 \pm 1.8$ & $10.9 \pm 2.9$ & $20.3 \pm 3.5$ & $1.05 \pm 0.03$ \\
MuT & $10.2 \pm 2.1$ & $12.9 \pm 8.5^{*}$ & $23.1 \pm 8.8^{*}$ & $1.02 \pm 0.09$ \\
OuT & $10.3 \pm 3.3$ & $12.7 \pm 5.9^{*}$ & $23.0 \pm 6.6^{*}$ & $1.30 \pm 0.13^{\S}$ \\
\hline
\end{tabular}

Values are means \pm SD. YT, young trained; MT, middle-aged trained; OT, older trained; YuT, young untrained; MuT, middle-aged untrained; OuT, older untrained; [HHb], deoxygenated hemoglobin concentration; TD, time delay; $\tau$, time constant of response; $\tau^{\prime}[\mathrm{HHb}]$, sum of $\tau[\mathrm{HHb}]$ and $\mathrm{TD}[\mathrm{HHb}] . *$, significantly different from age-matched trained group $(\mathrm{P}<0.05) ;{ }^{\dagger}$, significantly different from training-matched young group $(\mathrm{P}<0.05) ;{ }^{\S},[\mathrm{HHb}] / \mathrm{VO}_{2 \mathrm{p}}$ significantly different from $1.0(\mathrm{P}<0.05)$. 


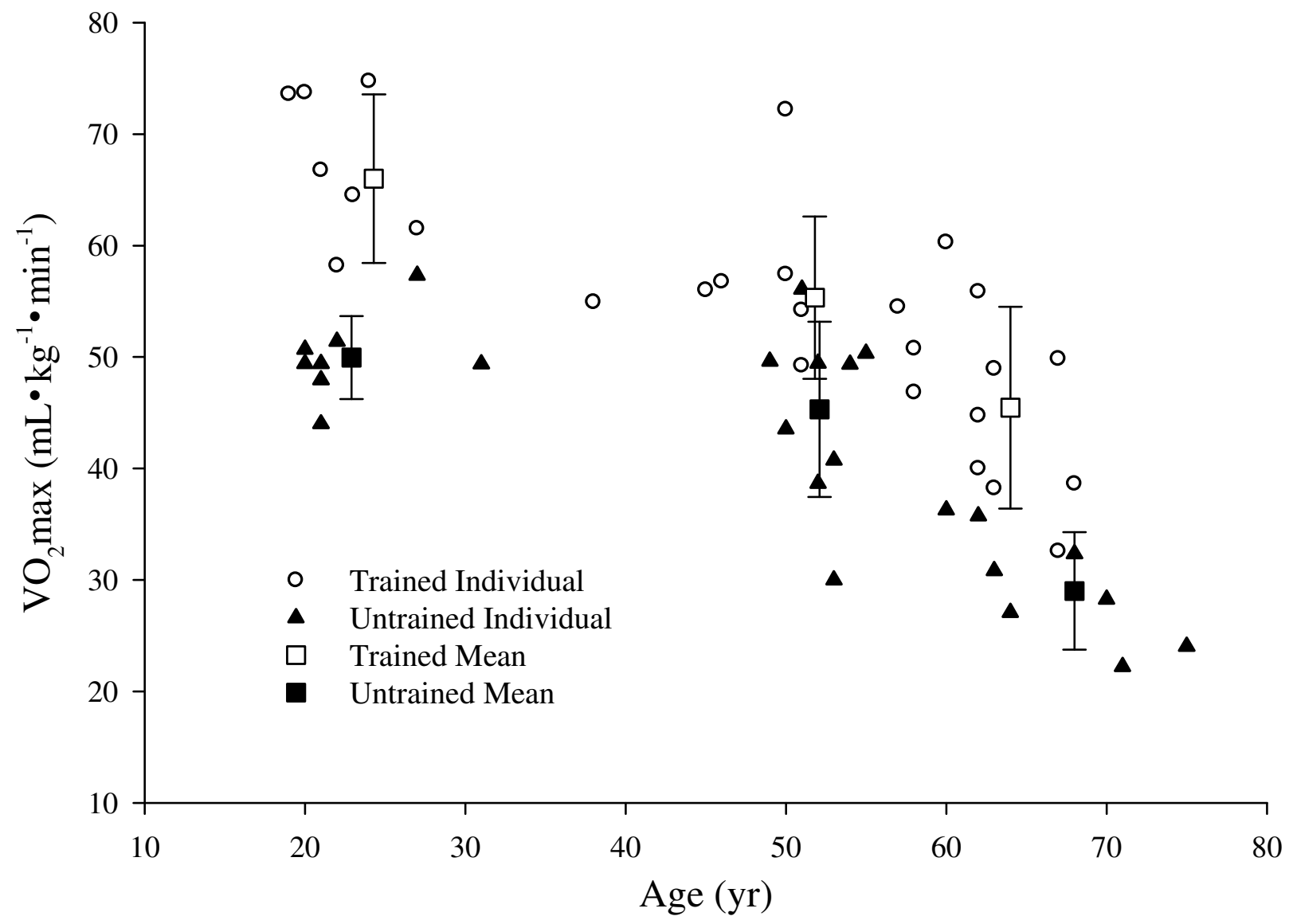

Fig. 1. Individual and average group $\mathrm{VO}_{2} \max \left(\mathrm{mL} \cdot \mathrm{kg}^{-1} \cdot \mathrm{min}^{-1}\right)$ values. Group values are mean \pm SD. 


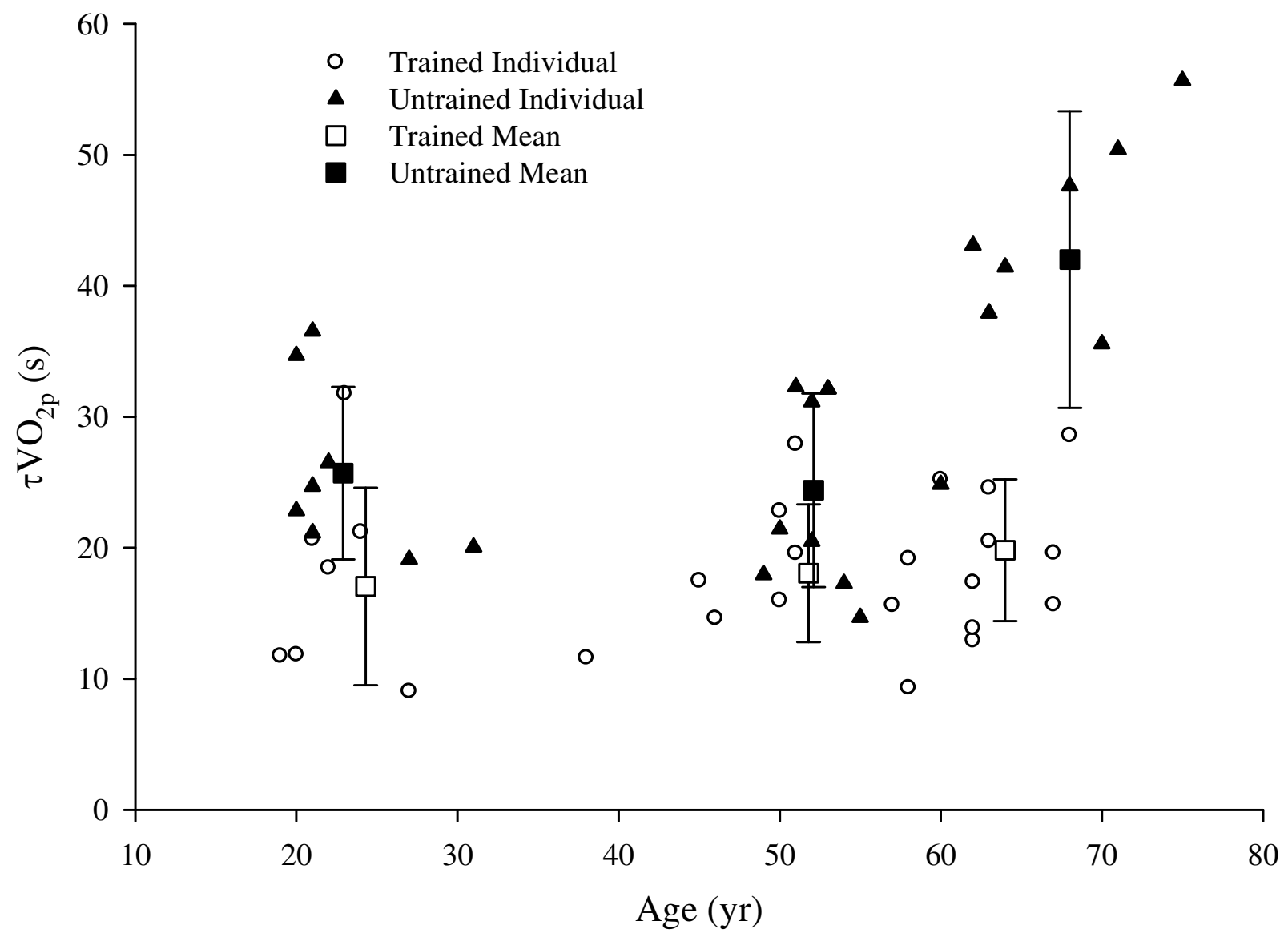

Fig. 2. Individual and average group $\tau \mathrm{VO}_{2 p}(\mathrm{~s})$ values. Group values are mean $\pm \mathrm{SD}$. 
Trained
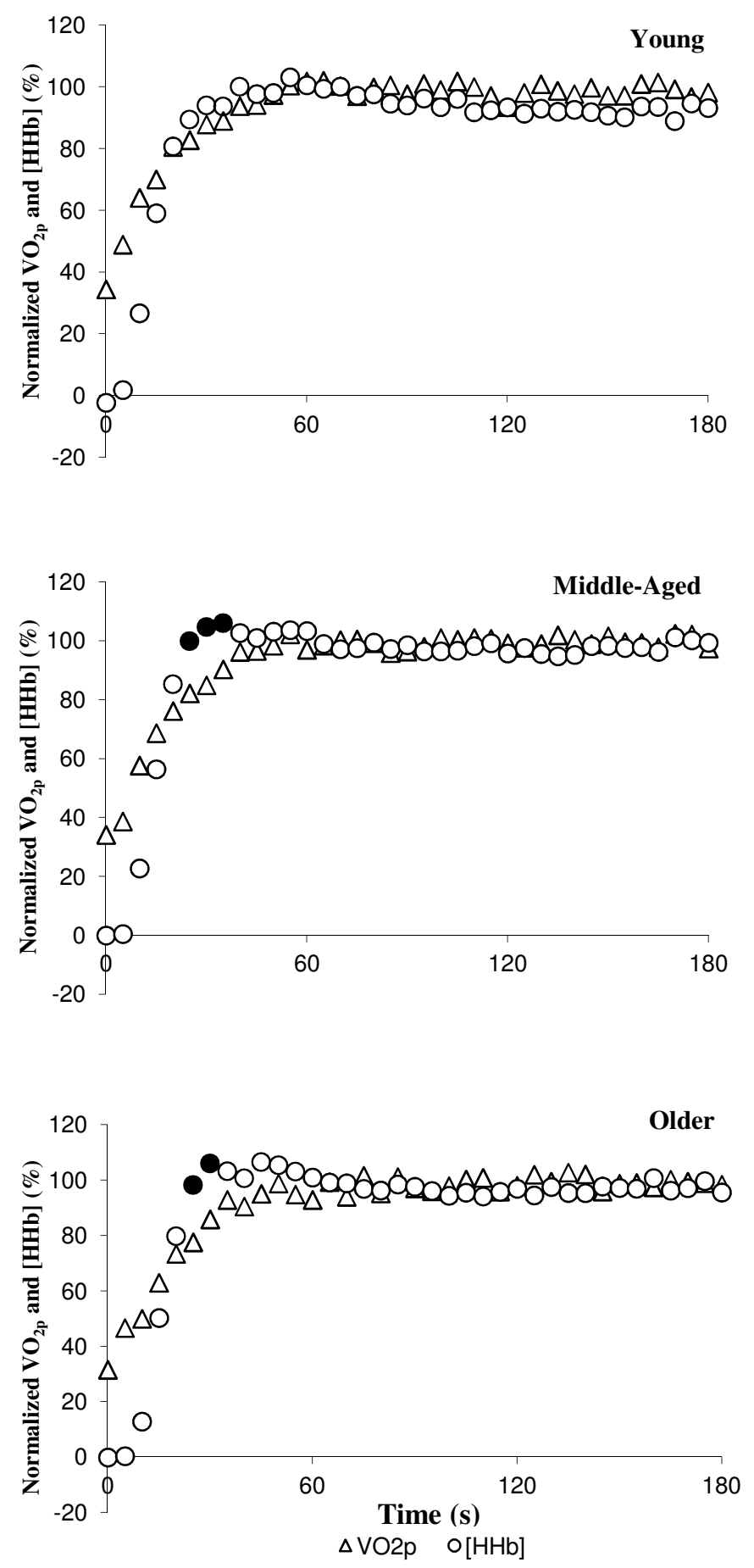

Untrained
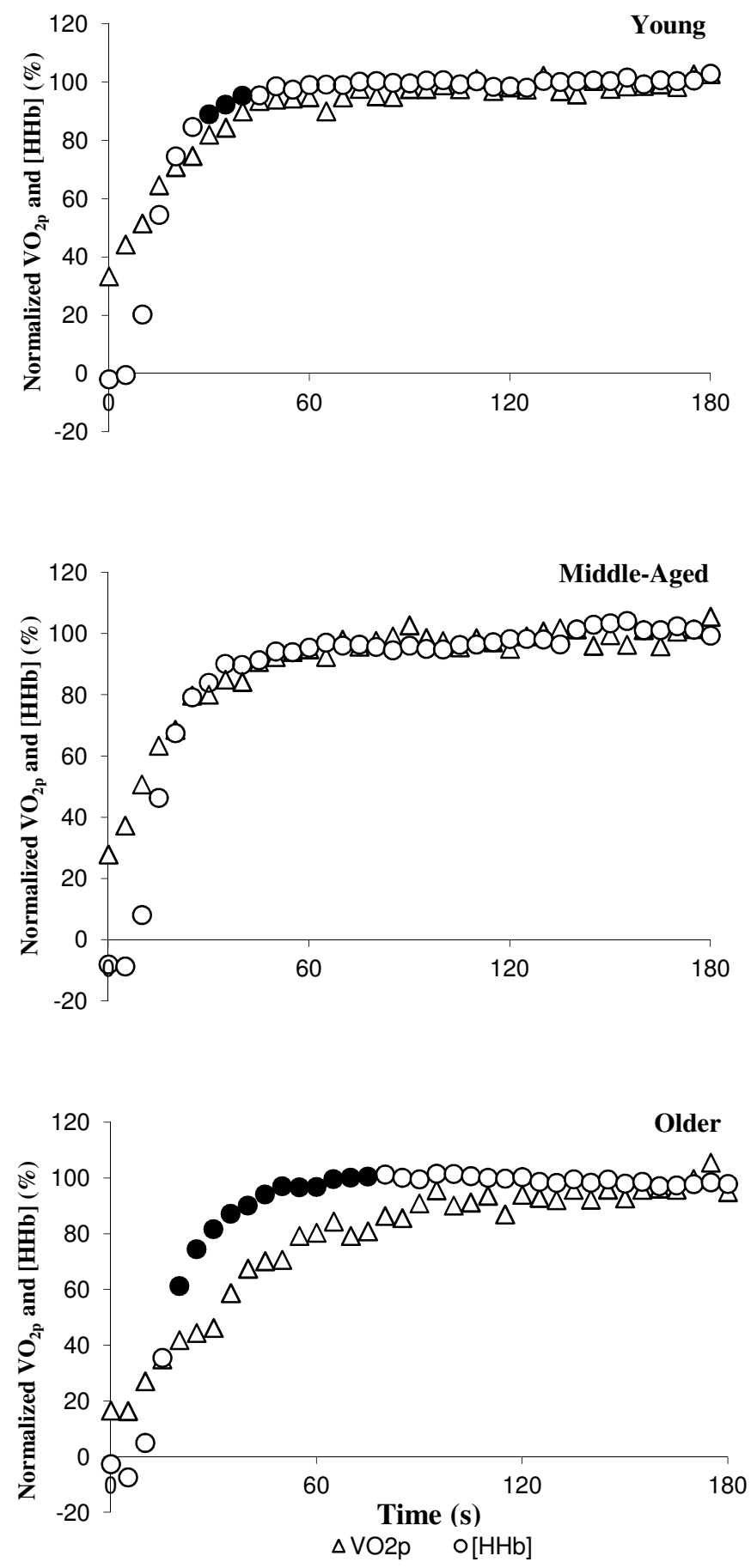

Fig. 3. Group mean profiles for the adjustment of $[\mathrm{HHb}]$ and $\mathrm{VO}_{2 \mathrm{p}}$ (left shifted such that data from

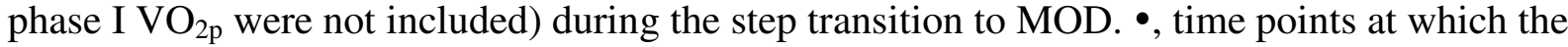
relative increase of $[\mathrm{HHb}]$ is greater than the relative increase of $\mathrm{VO}_{2 \mathrm{p}}(\mathrm{P}<0.05)$. 
Trained
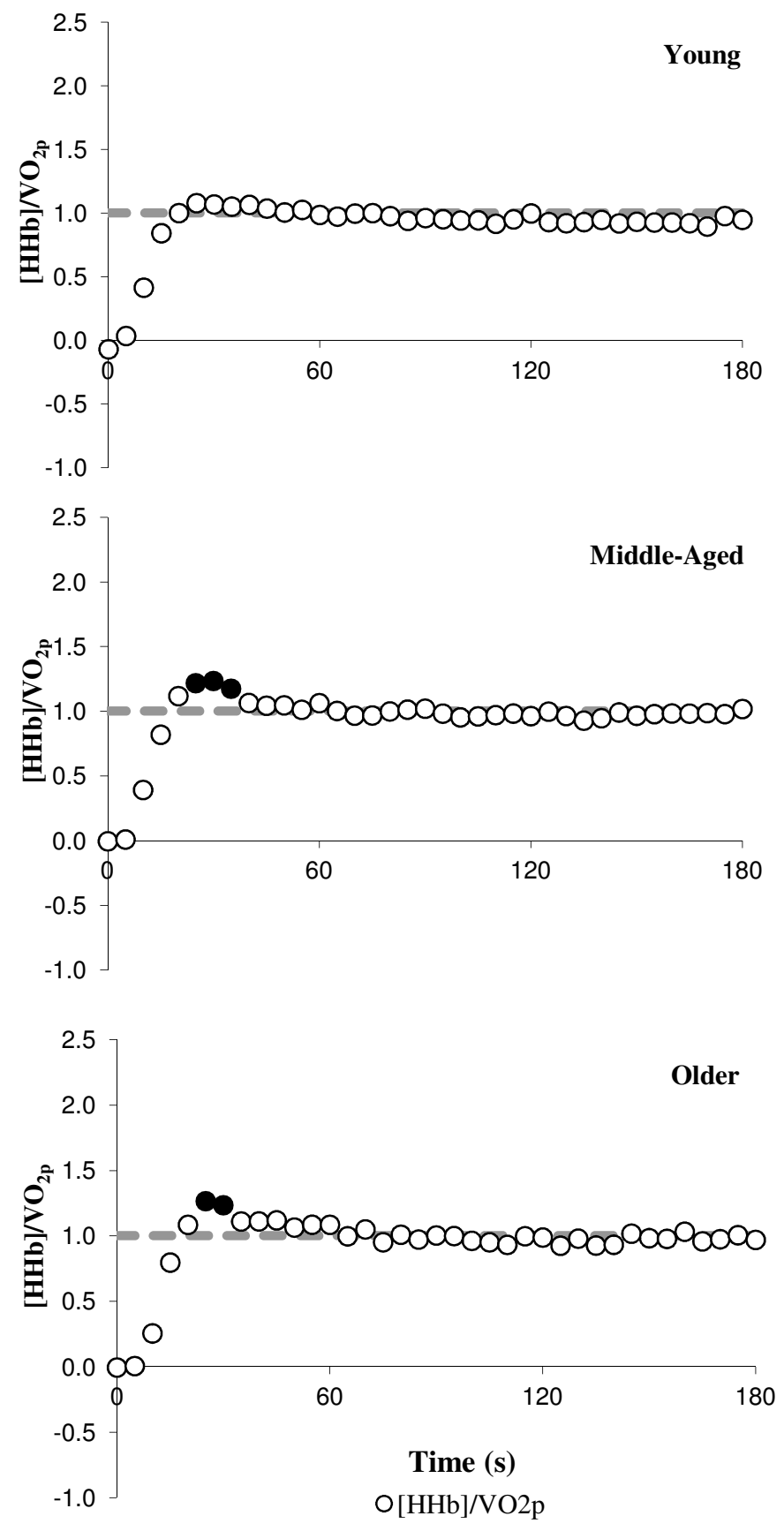
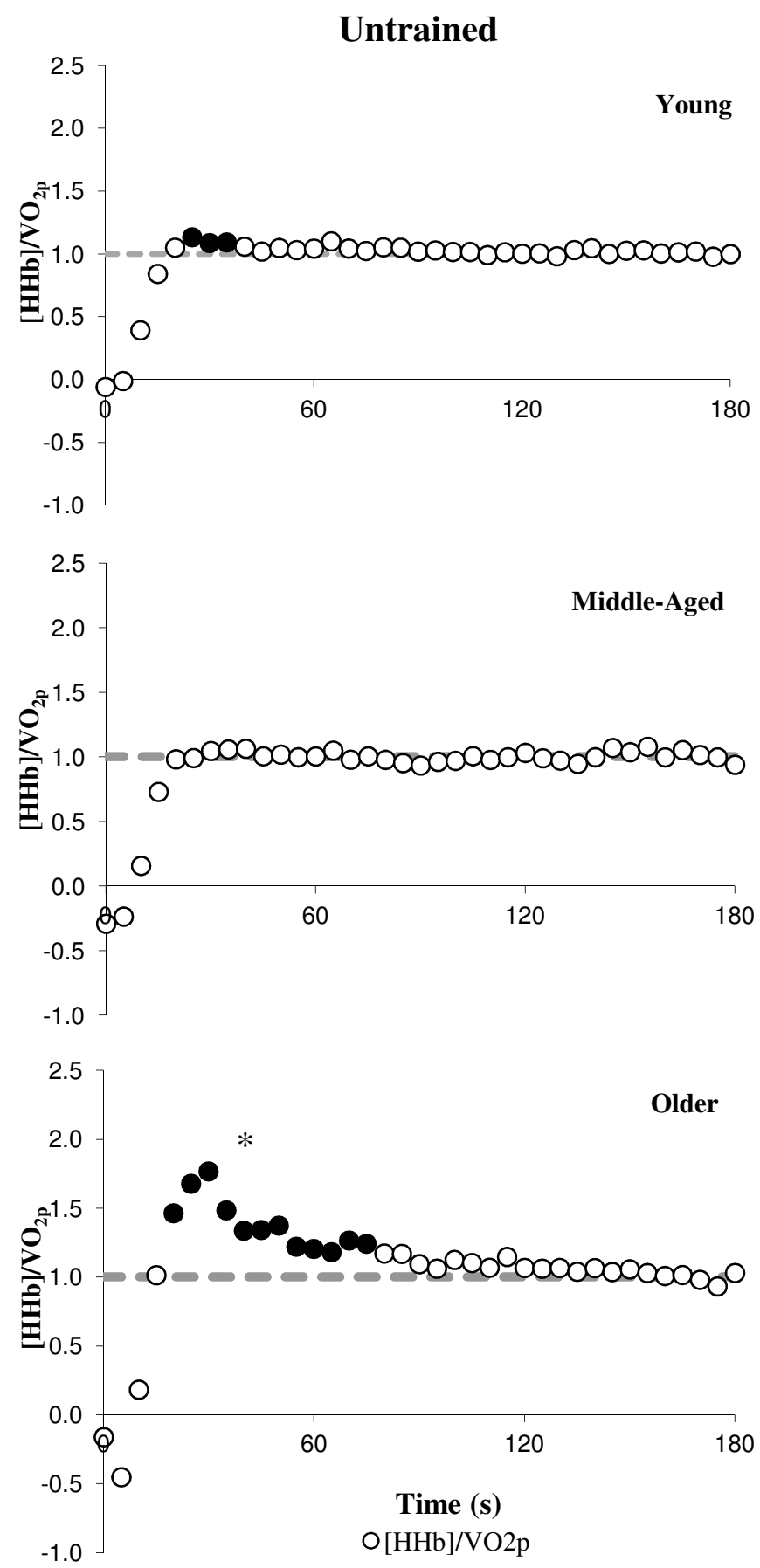

Fig. 4. Group mean profiles for the adjustment of $[\mathrm{HHb}] / \mathrm{VO}_{2 \mathrm{p}}$ during the step transition to MOD. ${ }^{\bullet}$, time points at which the relative increase of $[\mathrm{HHb}]$ is greater than the relative increase of $\mathrm{VO}_{2 \mathrm{p}}(\mathrm{P}<0.05)$. $*[\mathrm{HHb}] / \mathrm{VO}_{2 \mathrm{p}}$ significantly different from $1.0(\mathrm{P}<0.05)$. 


\subsection{DISCUSSION}

Numerous studies have examined the time course adjustment of $\mathrm{VO}_{2 \mathrm{p}}$ during the transitions to moderate-intensity exercise in young and older men (Chilibeck et al., 1997; DeLorey et al., 2004a, 2007; Gurd et al., 2008; Murias et al., 2010). Additionally, a couple of studies have reported the $\mathrm{VO}_{2}$ kinetics of middle-aged and older men (Berger et al., 2006a; Fukuoka et al., 2002). The present study examined the $\mathrm{VO}_{2}$ kinetic profiles of young, middleaged, and older endurance trained and untrained men. The main findings were as follows: 1) in the untrained groups, $\tau \mathrm{VO}_{2 \mathrm{p}}$ did not differ significantly between young to middle-aged, but was substantially greater in the older group; 2 ) in the chronically endurance-trained groups, $\tau \mathrm{VO}_{2 \mathrm{p}}$ did not change appreciably across age, and was always less than the untrained groups (only significantly $(\mathrm{P}<0.05)$ less than older untrained group); 3$)$ there was a significant $\left[\mathrm{HHb} / \mathrm{VO}_{2 \mathrm{p}}\right.$ "overshoot" during the exercise transition in the older untrained group indicating an $\mathrm{O}_{2}$ delivery limitation accompanying the slow $\mathrm{VO}_{2}$ kinetics.

Many studies have reported the age-related decline in $\mathrm{VO}_{2} \max$ (Beere et al., 1999; Betik \& Hepple, 2008; Fleg et al., 2005; Jackson et al., 1995; Pimental et al., 2003; Stathokostas et al., 2004; Trappe et al., 1996; Wilson \& Tanaka, 2000). The $\mathrm{VO}_{2} \mathrm{max}$ values in this study decreased

as a function of age for both training groups $\left(\sim 5 \mathrm{~mL} \cdot \mathrm{kg}^{-1} \bullet \mathrm{min}^{-1}\right.$ per decade), with each group having a significantly lower $\mathrm{VO}_{2} \max$ than the preceding training-matched younger group, and with endurance trained group values consistently greater than untrained, which is in accordance with the literature (Jackson et al., 1995; Pimental et al., 2003; Stathokostas et al., 2004; Wilson $\&$ Tanaka, 2000). Both trained and untrained groups showed similar rates of decline (8-9\% per decade) in $\mathrm{VO}_{2} \mathrm{max}$, which is also similar to the literature ( 6 - 10\%) (Fleg et al., 2005; Pimental et al., 2003; Stathokostas et al., 2004; Trappe et al., 1996; Wilson \& Tanaka, 2000). Previous cross-sectional (Pimental et al., 2003) and longitudinal (Fleg et al., 2005) studies have revealed an accelerated decline in $\mathrm{VO}_{2} \max$ with age, which also occurs in the present study. Fleg et al. (2005) found a $3-6 \%$ decline per decade in the 20 s and 30 s, and $>20 \%$ per decade in the 70 s and later; in the present study, the declines between young and middle-aged were 6 and 3\% (for trained and untrained, respectively), and between middle-aged and older were 15 and 23\% (for trained and untrained, respectively). Jackson et al. (1995) have partially attributed the accelerated decline in $\mathrm{VO}_{2} \max$ to an increase in body fat with age; thus, the increase in body mass (although 
not significant) with age in the present study partially contributes to the greater decline in $\mathrm{VO}_{2} \mathrm{max}$ at older age. The untrained subjects of the present study were recreationally active men, and had $\mathrm{VO}_{2}$ max values for young, middle-aged, and older, respectively, that were 14, 23 and $7 \%$ greater than the averages reported for an age-matched population (ACSM, 2013). Endurance trained groups were heavily trained and had $\mathrm{VO}_{2}$ max values for young, middle-aged, and older, respectively, that were 35,40 , and $36 \%$ greater than the averages reported for an age-matched population (ACSM, 2013). It should be considered that although training distances decreased with age, the level of activity in the middle-aged and older group ( $>10$ hours $^{\bullet}$ week $\left.^{-1}\right)$ was still considerably beyond that of recreationally active individuals at any age.

A number of studies have measured $\tau \mathrm{VO}_{2 \mathrm{p}}$ values in young untrained men (Berger et al., 2006b; Gurd et al., 2006, 2008; Koppo et al., 2004; McKay et al., 2009; Murias et al., 2010, 2012; Spencer et al., 2011, 2012); our group mean $\tau \mathrm{VO}_{2 p}$ values in young (26 s) are in agreement with these studies which reported a range between 21 and 34 s. Additionally, a number of studies have examined $\tau \mathrm{VO}_{2 p}$ values in older untrained men (Berger et al., 2006a; Chilibeck et al., 1996; Gurd et al., 2008; Murias et al., 2010); our group mean $\tau \mathrm{VO}_{2 \mathrm{p}}$ values in the old untrained (42 s) are also similar to that of the literature which reported a range between 40 and $55 \mathrm{~s}$. Furthermore, a number of training studies have measured the change in $\tau \mathrm{VO}_{2 \mathrm{p}}$ following endurance-training programs lasting $\leq 12$ weeks (Berger et al., 2006b; Fukuoka et al., 2002; Murias et al., 2010). These three training studies have shown a speeding of $\tau \mathrm{VO}_{2 \mathrm{p}}$ to an average of $\sim 23 \mathrm{~s}$ in young (Berger et al., 2006b; Murias et al., 2010) and 33 s in older (Fukuoka et al., 2002; Murias et al., 2010) men, whereas our values in the chronically endurance trained are lower in both young (17 s) and particularly in the older (20 s) group. The trained men of the present study have been training for more than a few years (averaging 6 in young and 23 years in older) and are considered long-term, chronically endurance trained, which is most likely the reason for the faster $\mathrm{VO}_{2}$ kinetics. Evidence to support this is found in one cross-sectional study in young (Koppo et al., 2004) and one in old (Berger el al., 2006a) looking at long-term, chronically endurance trained men. In these studies $\tau \mathrm{VO}_{2 p}$ values of $12 \mathrm{~s}$ for young (Koppo et al., 2004) and $29 \mathrm{~s}$ for older (Berger et al., 2006a) are fast relative to untrained, which is in accordance with our results (17 and $20 \mathrm{~s}$ for young and older, respectively). Therefore, studies of transient endurance training (i.e. $\leq 12$ week endurance training programs) in men did not show $\tau \mathrm{VO}_{2 \mathrm{p}}$ values reduced to as low as values seen in our long-term endurance trained young and older men. Thus, long- 
term endurance training appears to prevent the age-related slowing of $\mathrm{VO}_{2}$ kinetics, despite an age-related decline in $\mathrm{VO}_{2} \mathrm{max}$.

Few studies exist that have measured $\mathrm{VO}_{2}$ kinetics in the middle-aged population. Berger et al. (2006a) and Fukuoka et al. (2002) measured $\tau \mathrm{VO}_{2 \mathrm{p}}$ in untrained middle-aged men and found values averaging $\sim 48 \mathrm{~s}$, which are greater than the present study ( $24 \mathrm{~s}$ ). This discrepancy is possibly due to the difference in relative physical activity of the groups as the subjects in the present study were recreationally active and the subjects in their studies were sedentary. In our middle-aged group we found that in the chronic endurance training group the $\tau \mathrm{VO}_{2 p}(18 \mathrm{~s})$ demonstrated fast $\mathrm{VO}_{2}$ kinetics with a $\tau$ similar to that of younger endurance trained $(17 \mathrm{~s})$; whereas, other studies in middle-aged endurance-trained men did not reach such low values (Berger et al., 2006a; Fukuoka et al., 2002). Research groups examining middle-aged endurancetrained men via cross-sectional study (Berger et al., 2006a) or following a 90-day endurancetraining program (Fukuoka et al., 2002) found a speeding of $\tau \mathrm{VO}_{2 \mathrm{p}}$ to only 25 (Berger et al., 2006a) and 29 s (Fukuoka et al., 2002). In the end, the chronically endurance trained men of the present study were able to prevent the age-related slowing of $\mathrm{VO}_{2}$ kinetics, whereas transient endurance training programs are unable to speed $\mathrm{VO}_{2}$ kinetics to that of faster young endurancetrained.

Is the age-related slowing of $\mathrm{VO}_{2}$ kinetics attributable to lack of physical activity with age or rather aging itself? $\mathrm{VO}_{2} \mathrm{max}$ declined at similar rates in both trained and untrained groups, despite the endurance trained individuals being heavily active at all ages; thus, the decline in $\mathrm{VO}_{2}$ max does not necessarily indicate a decline in physical activity, but rather the natural loss in maximal cardiac output (Fuchi et al., 1989; Hagberg et al., 1985, Rowell, 1974; Wilson \& Tanaka, 2000). However, in individuals with chronically high levels of physical activity, the agerelated increase in $\tau \mathrm{VO}_{2 \mathrm{p}}$ was abolished, thus maintaining a $\mathrm{VO}_{2}$ kinetic profile similar to that of the young endurance trained. Therefore, individuals who are long-term heavily active are able to abolish the change in $\tau \mathrm{VO}_{2 \mathrm{p}}$ with age, and since $\tau \mathrm{VO}_{2 \mathrm{p}}$ is a sub-maximal measure, it is possible that a different mechanism exists (other than the mechanisms determining $\mathrm{VO}_{2} \max$ ) that governs the $\mathrm{VO}_{2}$ kinetic response with age. 
What mechanism or regulatory factor might constrain $\mathrm{VO}_{2}$ kinetics with age, which is abolished in long-term endurance training? A limitation in $\mathrm{O}_{2}$ delivery to the exercising muscle has been proposed as a likely mechanism regulating the rate of adaptation of oxidative phosphorylation (Murias et al., 2010, 2011b, 2012, 2014; Poole et al., 2008; Spencer et al., 2012). It has been hypothesized (Phillips et al., 1995) that faster femoral artery blood velocity (from endurance training) was responsible for reductions in $\tau \mathrm{VO}_{2 \mathrm{p}}$; however, measures of muscle conduit artery blood flow kinetics in young healthy adults have shown that the rate of adjustment is similar to or faster than that of $\mathrm{VO}_{2 p}$ (duManoir et al., 2010; MacPhee et al., 2005).

Furthermore, in a training study of older adults that resulted in faster $\mathrm{VO}_{2}$ kinetics, the kinetics of femoral artery mean blood velocity remained unchanged following training (Bell et al., 2001a).Therefore, bulk $\mathrm{O}_{2}$ delivery does not seem to be limiting $\mathrm{VO}_{2}$ kinetics or the adaptation to training that results in faster $\mathrm{VO}_{2}$ kinetics. Recent advancements in NIRS have allowed a continuous assessment of tissue deoxygenation at the exercising muscle, providing an index of $\mathrm{O}_{2}$ extraction and an insight into local microvascular $\mathrm{O}_{2}$ delivery. Our laboratory has applied this measure in conjunction with $\mathrm{VO}_{2}$ kinetics, to show a faster adjustment of the [HHb] signal than the adjustment of phase II $\mathrm{VO}_{2 \mathrm{p}}$ in individuals with relatively slow kinetics $\left(\tau \mathrm{VO}_{2 \mathrm{p}}>20 \mathrm{~s}\right)$ (DeLorey et al., 2004a; Murias et al., 2011b, 2012; Spencer et al., 2012); this is represented by a transient $[\mathrm{HHb}] / \mathrm{VO}_{2 \mathrm{p}}$ "overshoot." The overshoot relative to the $[\mathrm{HHb}] / \mathrm{VO}_{2 \mathrm{p}}$ ratio established at the steady-state response $\left(\right.$ ratio $=1.0$ ) indicates a greater fractional $\mathrm{O}_{2}$ extraction and thus poorer blood flow distribution to the active muscle. In the present study, only the older untrained group demonstrated a significant $[\mathrm{HHb}] / \mathrm{VO}_{2 \mathrm{p}}$ overshoot throughout the transition to moderate-intensity exercise; thus, older untrained men appear to have an $\mathrm{O}_{2}$ delivery limitation that is prevented by chronic endurance training.

It was noted in the present study that a "true" $[\mathrm{HHb}] / \mathrm{VO}_{2 \mathrm{p}}$ overshoot was shown only in the older untrained group. The young untrained and both middle-aged and older trained groups showed a brief overshoot that occurred relatively early in the exercise transition (from 25 to $\leq 35$ s), whereas in the older untrained group the overshoot extended from 20 to 75 s. It is noteworthy to mention that two subjects in each of the middle-aged and older endurance trained groups had a "true" overshoot of the $[\mathrm{HHb}]$ signal relative to its steady-state at $\sim 90 \mathrm{~s}$ into exercise (i.e. considerable overshoot in the $[\mathrm{HHb}]$ to that of $\sim 140-160 \%$ of steady-state), potentially leading to an overall group overshoot. Therefore, the overshoot in these groups (excluding older 
untrained) are likely not representative of an $\mathrm{O}_{2}$ distribution limitation to the working muscle groups occurring throughout the adjustment toward the steady-state relationship of the $[\mathrm{HHb}] / \mathrm{VO}_{2 \mathrm{p}}$.

The present study suggests that long-term or chronic training is required to maintain a $\mathrm{VO}_{2}$ kinetic profile similar to young endurance trained; whereas a previous study by Murias et al. (2010) examined the change in $\mathrm{VO}_{2}$ kinetics following a 12-week endurance training intervention in older adults. Murias et al. (2010) showed that in older individuals there is an $\mathrm{O}_{2}$ limitation that was reduced (following 3 weeks of endurance training) to that of regular healthy young, but with no change thereafter. The present study showed that chronically endurance trained older men displayed kinetics faster than young untrained and similar to young endurancetrained men, and the transient training study by Murias et al. (2010) could not speed $\mathrm{VO}_{2}$ kinetics beyond young untrained. Consequently, it appears that chronic endurance training can prevent and abolish the $\mathrm{O}_{2}$ delivery limitation, whereas transient multi-week training regimes only partially improve the $\mathrm{VO}_{2}$ kinetic limitation.

The $\mathrm{O}_{2}$ delivery limitation (poorer microvascular blood flow) in the older untrained group, represented as the transient overshoot in the $[\mathrm{HHb}] / \mathrm{VO}_{2 \mathrm{p}}$ ratio, could be explained by a reduced endothelium-dependent vasodilation compared to younger or more active individuals (DeSouza et al., 2000). In regard to aging, animal studies have shown that endotheliumdependent vasodilation was reduced in feed arteries and 1A-arterioles of oxidative soleus muscles in older but not young rats (Muller-Delp et al., 2002), which could contribute to an impaired blood flow distribution. Interestingly, exercise training was shown to restore both flow(Spier et al., 2007) and endothelium- (Spier et al., 2004) dependent vasodilation in the soleus muscle arterioles of older rats. In humans, DeSouza et al. (2000) tested both chronically endurance-trained individuals and sedentary individuals after 3 months of aerobic endurance training, and found that endurance training could restore (in sedentary older men following endurance training) or prevent (in the chronically endurance trained) the age-related decline in endothelium-dependent vasodilation. This amelioration potentially occurs via a nitric oxide synthase (NOS) dependent mechanism, in which the active tissue increases endothelium-NOS protein expression (Seals et al., 2008; Spier et al., 2004). Therefore, enhancement of endothelium-dependent vasodilation may be responsible for improved blood flow delivery at 
exercise onset, and thereby abolish the $[\mathrm{HHb}] / \mathrm{VO}_{2 \mathrm{p}}$ overshoot that is seen in older untrained men and absent in older trained men of the present study.

Complimentary to functional changes at the active muscle, structural improvements (i.e. increased capillarization) have also been measured following endurance training (Coggan et al., 1990, 1992; Murias et al., 2011a). Murias et al. (2011a) found increases in capillarization of 20$30 \%$ in young and $30-40 \%$ in older males within a 12-week endurance training program. Additionally, Coggan et al. (1992) have shown similar improvements in capillary density (increases of 21\%) following 9-12 months of endurance training in older men. In chronically trained masters athletes, Coggan et al. (1990) found capillary densities that were similar to that of training-matched young athletes. The results of these studies suggest that short- and long-term endurance training is associated with substantial gains in capillarization, which reflects better $\mathrm{O}_{2}$ delivery and the potential for improved $\mathrm{O}_{2}$ distribution. Increases in capillarization indicate that a larger surface area is available for $\mathrm{O}_{2}$ exchange, suggesting an elevated $\mathrm{O}_{2}$ flux capacity exists between the capillaries and the muscle fibers (Hepple et al., 1997). These structural changes, accompanied by the improvements in endothelium-NOS protein expression, indicate that endurance training profoundly improves blood flow delivery and thus $\mathrm{O}_{2}$ flux at the onset of exercise.

\section{Limitations:}

Although the present study was interested in the three age groups, in order to distinguish age-related changes in $\mathrm{VO}_{2}$ kinetics across all ages a greater representation of (trained and untrained) men aged 30 to 45 in particular, would be required; larger and more homogenous groups (in terms of activity level), which better represent the average population would be more ideal. A limitation also lies in the subject recruitment. The untrained individuals were recreationally active, and although not participating in systemic training program, were involved in an active lifestyle; it is difficult to know whether the "degree" of activity was similar across age groups and this could affect whether the $\mathrm{VO}_{2} \max$ and the $\tau \mathrm{VO}_{2 p}$ were different between agegroups. Nevertheless, based on their relative cardiorespiratory fitness (i.e. $\mathrm{VO}_{2}$ max values that were $7-23 \%$ above average) the untrained men seem to be similar representations of the population at each age group. It would be of interest to study sedentary individuals, however a difficulty lies within recruiting a truly sedentary population. Additionally, the endurance trained 
cyclists are not uniformly trained; each individual cyclist abides by his own fitness regime, which varies with age in distance and number of rides per week. Nevertheless, all trained cyclists were heavily active with cardiorespiratory fitness levels $\left(\mathrm{VO}_{2} \max \right) 35-40 \%$ greater than the average population.

\section{Conclusion:}

In summary, the age-related slowing of $\mathrm{VO}_{2}$ kinetics can be attenuated with short-term endurance training (Murias et al., 2010) in young and older; however, the present study demonstrated that long-term endurance training is required to abolish the age-related slowing of $\mathrm{VO}_{2}$ kinetics and maintain $\tau \mathrm{VO}_{2 \mathrm{p}}$ values comparable to young endurance trained. The slower $\mathrm{VO}_{2}$ kinetics in the older untrained group was associated with an $[\mathrm{HHb}] / \mathrm{VO}_{2 \mathrm{p}}$ overshoot, indicating an $\mathrm{O}_{2}$ delivery limitation. The older endurance trained group (with $\tau \mathrm{VO}_{2 \mathrm{p}}$ values similar to young endurance trained) did not present a "true" $[\mathrm{HHb}] / \mathrm{VO}_{2 \mathrm{p}}$ overshoot, suggesting long-term endurance training provides functional (enhanced endothelium-dependent vasodilation) as well as structural (increased capillarization) improvements in order to abolish the $\mathrm{O}_{2}$ delivery limitation associated with normal aging. 


\section{REFERENCE LIST}

American College of Sports Medicine (ACSM). (2013). Guidelines for Exercise Testing and Prescription $\left(9^{\text {th }}\right.$ ed.). Baltimore, MD: Lippincott Williams \& Wilkins.

Babcock MA, Paterson DH, Cunningham DA. (1992). Influence of ageing on aerobic parameters determined from a ramp test. Eur J Appl Physiol. 65: 138-143.

Babcock MA, Paterson DH, Cunningham DA. (1994a). Effects of aerobic endurance training on gas exchange kinetics of older men. Med Sci Sports Exerc. 26: 447-452

Babcock MA, Paterson DH, Cunningham DA, Dickinson JR. (1994b). Exercise on-transient gas exchange kinetics are slowed as a function of age. Med Sci Sports Exerc. 26: 440-446.

Bangsbo J, Gibala MJ, Krustrup P, Gonzalez-Alonso J, Saltin B. (2002). Enhanced pyruvate dehydrogenase activity does not affect muscle $\mathrm{O}_{2}$ uptake at onset of intense exercise in humans. Am J Physiol. 282: R273-280.

Beaver WL, Lamarra N, Wasserman K. (1981). Breath-by-breath measurement of true alveolar gas exchange. J Appl Physiol. 51: 1662-1675.

Beaver WL, Wasserman K, Whipp BJ. (1986). A new method for detecting anaerobic threshold by gas exchange. J Appl Physiol. 60: 2020-2027.

Beere PA, Russell SD, Morey MC, Kitzman DW, Higginbotham MB. (1999). Aerobic exercise training can reverse age-related peripheral circulatory changes in healthy older men. Circulation. 100: 1085-1094.

Bell C, Paterson DH, Kowalchuk JM, Cunningham DA. (1999). Oxygen uptake kinetics of older humans are slowed with age but are unaffected by hyperoxia. Experimental Physiology. 84: 747-759.

Bell C, Paterson DH, Kowalchuk JM, Moy AP, Thorp DB, Noble EG, Taylor AW, Cunningham DA. (2001a). Determinants of oxygen uptake kinetics in older humans following single-limb endurance exercise training. Exp Physiol. 86: 659-665. 
Bell C, Paterson DH, Kowalchuk JM, Padilla J, Cunningham DA. (2001b). A comparison of modelling techniques used to characterise oxygen uptake kinetics during the on-transient of exercise. Exp Physiol. 86: 667-676.

Berger NJA, Rittweger J, Kwiet A, Michaelis I, Williams AG, Tolfrey K, Jones AM. (2006a). Pulmonary $\mathrm{O}_{2}$ uptake on-kinetics in endurance- and sprint-trained master athletes. Int J Sports Med. 27: 1005-1012.

Berger NJA, Tolfrey K, Williams AG, Jones AM. (2006b). Influence of continuous and interval training on oxygen uptake on-kinetics. Med Sco Sports Exerc. 38(3): 504-512.

Betik AC \& Hepple RT. (2008). Determinants of $\mathrm{VO}_{2}$ max decline with aging: an integrated perspective. Appl Physiol nutr metab. 33: 130-140.

Chilibeck PD, McCreary CR, Marsh GD, Paterson DH, Noble EG, Taylor AW, Thompson RT. (1998). Evaluation of muscle oxidative potential by ${ }^{31} \mathrm{P}$-MRS during incremental exercise in old and young humans. Eur J Appl Physiol. 78: 460-465.

Chilibeck PD, Paterson DH, Petrella RJ, Cunningham DA. (1996). The influence of age and cardiorespiratory fitness on kinetics of oxygen uptake. Can J Appl Physiol. 21(3): 185-196.

Coggan AR, Spina RJ, King DS, Rogers MA, Brown M, Nemeth PM, Holloszy JO. (1992). Skeletal muscle adaptations to endurance training in 60- to 70-yr-old men and women. $J$ Appl Physiol. 72: 1780-1786.

Coggan AR, Spina RJ, Rogers MA, King DS, Brown M, Nemeth PM, Holloszy JO. (1990). Histochemical and enzymatic characteristics of skeletal muscle in master athletes. $J$ Appl Physiol. 68(5): 1896-1901.

Cunningham DA, Himann JE, Paterson DH, Dickinson JR. (1993). Gas exchange dynamics with sinusoidal work in young and elderly women. Respir Physiol. 91:43-56.

DeLorey DS, Kowalchuk JM, Paterson DH. (2004a). Effect of age on $\mathrm{O}_{2}$ uptake kinetics and the adaptation of muscle deoxygenation at the onset of moderate-intensity cycling exercise. $J$ Appl Physiol. 97: 165-172. 
DeLorey DS, Kowalchuk JM, Paterson DH. (2004b). Effect of prior heavy-intensity exercise on pulmonary $\mathrm{O}_{2}$ uptake and muscle deoxygenation kinetics in young and older adult humans. $J$ Appl Physiol. 97: 998-1005.

DeLorey DS, Paterson DH, Kowalchuk JM. (2007). Effects of ageing on muscle $\mathrm{O}_{2}$ utilization and muscle oxygenation during the transition to moderate-intensity exercise. Appl Physiol Nutr Metab. 32: 1251-1262.

DeLorey DS, Shaw CN, Shoemaker JK, Kowalchuk JM, Paterson DH. (2004c). The effect of hypoxia on pulmonary $\mathrm{O}_{2}$ uptake, leg blood flow and muscle deoxygenation during single-leg knee-extension exercise. Exp Physiol. 89(3): 293-302.

DeSouza CA, Shapiro LF, Clevenger CM, Dinenno FA, Monahan KD, Tanaka H, Seals DR. (2000). Regular aerobic exercise prevents and restores age-related declines in endotheliumdependent vasodilation in healthy men. Circulation. 102: 1351-1357.

Dogra S, Spencer MS, Murias JM, Paterson DH. (2013). Oxygen uptake kinetics in endurancetrained and untrained postmenopausal women. Appl Physiol Nutr Metab. 38: 154-160.

duManoir GR, DeLorey DS, Kowalchuk JM, Paterson DH. (2010). Kinetics of $\mathrm{VO}_{2}$ limb blood flow and regional muscle deoxygenation in young adults during moderate intensity, kneeextension exercise. Eur J Appl Physiol. 108: 607-617.

Fitzgerald MD, Tanaka H, Tran ZV, Seals DR. (1997). Age-related declines in maximal aerobic capacity in regularly exercising vs. sedentary women: a meta-analysis. J Appl Physiol. 83(1): 160-165.

Fleg JL, Morrell CH, Bos AG, Brant LJ, Talbot LA, Wright JG, Lakatta EG. (2005). Accelerated longitudinal decline of aerobic capacity in healthy older adults. Circulation. 112: 674-682.

Fuchi T, Iwaoka K, Higuchi M, Kobayashi S. (1989). Cardiovascular changes associated with decreased aerobic capacity and aging in long-distance runners. Eur J Appl Physiol. 58: 884889. 
Fukuoka Y, Grassi B, Conti M, Guiducci D, Sutti M, Marconi C, Cerretelli P. (2002). Early effects of exercise training on $\mathrm{VO}_{2}$ on- and off-kinetics in 50-year-old subjects. Pflugers Arch. 443: 690-697.

Grassi B, Gladden LB, Stary CM, Wagner PD, Hogan MC. (1998). Peripheral O $\mathrm{O}_{2}$ diffusion does not affect $\mathrm{VO}_{2}$ on-kinetics in isolated in situ canine muscle. J Appl Physiol Resp Env Exerc Physiol. 85: 1404-1412.

Grassi B, Hogan MC, Greenhaff PL, Hamann JJ, Kelley KM, Aschenbach WG, ConstantinTeodosiu D, Gladden LB. (2002). Oxygen uptake on-kinetics in dog gastrocnemius in situ following activation of pyruvate dehydrogenase by dichloroacetate. J Physiol. 538: 195-207.

Grassi B, Poole DC, Richardson RS, Knight DR, Erickson BK, Wagner PD. (1996). Muscle $\mathrm{O}_{2}$ uptake kinetics in humans: implications for metabolic control. J Appl Physiol. 80(3): 988-998.

Grassi B, Rossiter HB, Hogan MC, Howlett RA, Harris JE, Goodwin ML, Dobson JL, Gladden LB. (2011). Faster $\mathrm{O}_{2}$ uptake kinetics in canine skeletal muscle in situ after acute creatine kinase inhibition. J Physiol. 589(1): 221-233.

Gurd BJ, Peters SJ, Heigenhauser GJF, LeBlanc PJ, Doherty TJ, Paterson DH, Kowalchuk JM. (2006). Prior heavy exercise elevates pyruvate dehydrogenase activity and speeds $\mathrm{O}_{2}$ uptake kinetics during subsequent moderate-intensity exercise in healthy young adults. $J$ Physiol. 577(3): 985-996.

Gurd BJ, Peters SJ, Heigenhauser GJF, LeBlanc PJ, Doherty TJ, Paterson DH, Kowalchuk JM. (2008). $\mathrm{O}_{2}$ uptake kinetics, pyruvate dehydrogenase activity, and muscle deoxygenation in young and older adults during the transition to moderate-intensity exercise. Am J Physiol Regul Integr Comp Physiol. 294: R577-R584.

Hagberg JM, Allen WK, Seals DR, Hurley BF, Ehsani AA, Holloszy JO. (1985). A hemodynamic comparison of young and older endurance athletes during exercise. $J$ Appl Physiol. 58(6): 2041-2046. 
Hepple RT, Mackinnon SL, Goodman JM, Thomas SG, Plyley MJ. (1997). Resistance and aerobic training in older men: effects on $\mathrm{VO}_{2 \text { peak }}$ and the capillary supply to skeletal muscle. $J$ Appl Physiol. 82: 1305-1310.

Howlett RA, Heigenhauser GJ, Hultman E, Hollidge-Horvat MG, Spriet LL. (1999). Effects of dichloroacetate infusion on human skeletal muscle metabolism at the onset of exercise. Am J Physiol. 277: E18-25.

Hughson RL. (1984). Alterations in oxygen deficit-oxygen debt relationships with betaadrenergic receptor blockade in man. J Physiol. 349: 375-387

Hughson RL, Cochrane JE, Butler GC. (1993). Faster $\mathrm{O}_{2}$ uptake kinetics at onset of supine exercise with than without lower body negative pressure. J Appl Physiol. 75: 1962-1967.

Hughson RL \& Kowalchuk JM. (1995). Kinetics of oxygen uptake for submaximal exercise in hyperoxia, normoxia, and hypoxia. Can J Appl Physiol. 20(2): 198-210.

Jackson AS, Beard EF, Weir LT, Ross RM, Stuteville JE, Blair SN. (1995). Changes in aerobic power of men, ages 25-70 yr. Med Sci Sports Exerc. 27(1): 113-120.

Jones AM, Koppo K, Wilkerson DP, Wilmshurst S, Campbell IT. (2004). Dichloroacetate does not speed phase II pulmonary $\mathrm{VO}_{2}$ kinetics following the onset of heavy intensity cycle exercise. Pflugers Archives. 447: 867-874.

Koga S, Poole DC, Shiojiri T, Kondo N, Fukuba Y, Miura A, Barstow TJ. (2005). Comparison of oxygen uptake kinetics during knee extension and cycle exercise. Am J Physiol Regul Integr Comp Physiol. 288:R212-220.

Koppo K, Bouckaert J, Jones AM. (2004). Effects of training status and exercise intensity on phase II $\mathrm{VO}_{2}$ kinetics. Med Sci Sports Exerc. 36: 225-232.

MacDonald MJ, Pedersen PK, Hughson RL. (1997). Acceleration of $\mathrm{VO}_{2}$ kinetics in heavy submaximal exercise by hyperoxia and prior high-intensity exercise. J Appl Physiol: Resp Env Exerc Physiol. 83: 1318-1325. 
MacDonald MJ, Shoemaker JK, Tschakovsky ME, Hughson RL. (1998). Alveolar oxygen uptake and femoral artery blood flow dynamics in upright and supine leg exercise in humans. J Appl Physiol. 85: 1622-1628.

MacPhee SL, Shoemaker JK, Paterson DH, Kowalchuk JM. (2005). Kinetics of $\mathrm{O}_{2}$ uptake, leg blood flow, and muscle deoxygenation are slowed in the upper compared with lower region of the moderate-intensity exercise domain. J Appl Physiol. 99: 1822-1834.

McCreary CR, Chilibeck PD, Marsh GD, Paterson DH, Thompson RT. (1996). Kinetics of pulmonary oxygen uptake and muscle phosphates during moderate intensity calf exercise. $J$ Appl Physiol. 81: 1331-1338.

McKay BR, Paterson DH, Kowalchuk JM. (2009). Effect of short-term high-intensity interval training vs. continuous training on $\mathrm{O}_{2}$ uptake kinetics, muscle deoxygenation, and exercise performance. J Appl Physiol. 107: 128-138.

Muller-Delp JM, Spier SA, Ramsey MW, Delp MD. (2002). Aging impairs endotheliumdependent vasodilation in rat skeletal muscle arterioles. Am J Physiol Heart Circ Physiol. 283(4): H1662-H1672.

Murias JM, Kowalchuk JM, Paterson DH. (2010). Speeding of $\mathrm{VO}_{2}$ kinetics with endurance training in old and young men is associated with improved matching of local $\mathrm{O}_{2}$ delivery to muscle $\mathrm{O}_{2}$ utilization. J Appl Physiol. 108: 913-922.

Murias JM, Kowalchuk JM, Ritchie D, Hepple RT, Doherty TJ, Paterson DH. (2011a). Adaptations in capillarization and citrate synthase activity in response to endurance training in older and young men. J Gerontol A Biol Sci Med Sci. 66A(9): 957-964.

Murias JM, Spencer MS, Kowalchuk JM, Paterson DH. (2011b). Muscle deoxygenation to $\mathrm{VO}_{2}$ relationship differs in young subjects with varying $\tau \mathrm{VO}_{2}$. Eur J Appl Physiol. 111: 3107-3118.

Murias JM, Spencer MD, Paterson DH. (2014). The critical role of $\mathrm{O}_{2}$ provision in the dynamic adjustment of oxidative phosphorylation. Exerc Sport Sci Rev. 42(1): 4-11. 
Murias JM, Spencer MD, Pogliaghi S, Paterson DH. (2012). Noninvasive estimation of microvascular $\mathrm{O}_{2}$ provision during exercise on-transients in healthy young males. Am J Physiol Regul Integr Comp Physiol. 303: R815-R823.

Musch TI, Eklund KE, Hageman KS, Poole DC. (2004). Altered regional blood flow responses to submaximal exercise in older rats. J Appl Physiol. 96: 81-88.

Paterson DH \& Cunningham DA. (1999). The gas transporting systems: limits and modifications with age and training. Can J Appl Physiol. 24(1): 28-40.

Paterson DH, Cunningham DA, Koval JJ, St. Croix CM. (1999). Aerobic fitness in a population of independently living men and women aged 55-86 years. Med Sci Sports Exerc. 31(12): 1813-1820.

Paterson DH \& Whipp BJ. (1991). Asymmetries of oxygen uptake transients at the on- and offset of heavy exercise in humans. J Physiol. 443: 575-586.

Pimentel AE, Gentile CL, Tanaka H, Seals DR, Gates PE. (2003). Greater rate of decline in maximal aerobic capacity with age in endurance-trained than in sedentary men. $J$ Appl Physiol. 94: 2406-2413.

Phillips SM, Green HJ, MacDonald MJ, Hughson RL. (1995). Progressive effect of endurance training on $\mathrm{VO}_{2}$ kinetics at the onset of submaximal exercise. J Appl Physiol. 79: 1914-1920.

Poole DC, Barstow TJ, McDonough P, Jones AM. (2008). Control of oxygen uptake during exercise. Med Sci Sports Exerc. 40: 462-474.

Rogers MA, Hagberg JM, Martin WH, Ehsani AA, Holloszy JO. (1990). Decline in $\mathrm{VO}_{2} \mathrm{max}$ with aging in masters athletes and sedentary men. J Appl Physiol. 68(5): 2195-2199.

Rossiter HB, Ward SA, Doyle VL, Howe FA, Griffith JR, Whipp BJ. (1999). Inferences from pulmonary $\mathrm{O}_{2}$ uptake with respect to intramuscular [phosphocreatine] kinetics during moderate exercise in humans. J Physiol. 518(3): 921-932. 
Rossiter HB, Ward SA, Howe FA, Wood DM, Kowalchuk JM, Griffiths JR, Whipp BJ. (2003). Effects of dichloroacetate on $\mathrm{VO}_{2}$ and intramuscular 21P metabolite kinetics during highintensity exercise in humans. J Appl Physiol: Resp Env Exer Physiol. 95: 1105-1115.

Rowell LB. (1974). Human cardiovascular adjustments to exercise and thermal stress. Physiol Rev. 54: 75-159.

Scheuermann BW, Bell C, Paterson DH, Barstow TJ, Kowalchuk JM. (2002). Oxygen uptake kinetics for moderate exercise are speeded in older humans by prior heavy exercise. $J$ Appl Physiol. 92: 609-616.

Seals DR, DeSouza CA, Donato AJ, Tanaka H. (2008). Habitual exercise and arterial aging. $J$ Appl Physiol. 105: 1323-1332.

Spencer MD, Murias JM, Grey TM, Paterson DH. (2012). Regulation of $\mathrm{VO}_{2}$ kinetics by $\mathrm{O}_{2}$ delivery: insights from acute hypoxia and heavy-intensity priming exercise in young men. $J$. Appl. Physiol 112(6): 1023-1032.

Spencer MD, Murias JM, Lamb HP, Kowalchuk JM, Paterson DH. (2011). Are the parameters of $\mathrm{VO}_{2}$, heart rate, and muscle deoxygenation kinetics affected by serial moderate-intensity exercise transitions in a single day? Eur J Appl Physiol. 111: 591-600.

Spier SA, Delp MD, Meininger CJ, Donato AJ, Ramsey MW, Muller-Delp JM. (2004). Effects of ageing and exercise training on endothelium-dependent vasodilation and structure of rat skeletal muscle arterioles. J Physiol. 556(3): 947-958.

Spier SA, Delp MD, Stallone JN, Dominguez JM 2 ${ }^{\text {nd }}$, Muller-Delp JM. (2007). Exercise training enhances flow-induced vasodilation in skeletal muscle resistance arteries of aged rats: role of $\mathrm{PGI}_{2}$ and nitric oxide. Am J Physiol Heart Circ Physiol. 292: H3119-H3127.

Springer C, Barstow TJ, Wasserman K, Cooper DM. (1991). Oxygen uptake and heart rate response during hypoxic exercise in children and adults. Med Sci Sports Exerc. 23(1): 71-79.

Stathokostas L, Jacob-Johnson S, Petrella RJ, Paterson DH. (2004). Longitudinal changes in aerobic power in older men and women. J Appl Physiol. 97: 784-789. 
Tanaka H, DeSouza CA, Jones PP, Stevenson ET, Davy KP, Seals DR. (1997). Greater rate of decline in maximal aerobic capacity with age in physically active vs. sedentary healthy women. J Appl Physiol. 83(6): 1947-1953.

Trappe SW, Costill DL, Vukovich MD, Jones J, Melham T. (1996). Aging among elite distance runners: a 22-yr longitudinal study. J Appl Physiol. 80(1): 285-290.

Whipp BJ. (1971). Rate constant for the kinetics of oxygen uptake during light exercise. $J$ Appl Physiol. 30(2): 261-263.

Whipp BJ \& Wasserman K. (1972). Oxygen uptake kinetics for various intensities of constantload work. J Appl Physiol. 33(3): 351-356.

Wilson TM \& Tanaka H. (2000). Meta-analysis of the age-associated decline in maximal aerobic capacity in men: relation to training status. Am J Physiol Heart Circ Physiol. 278: H829H834. 


\section{APPENDIX A: ETHICS APPROVAL NOTICE}

Principal Investigator: Dr. Donald Paterson

Review Number: 18148

Review Level: Full Board

Approved Local Adult Participants: 48

Approved Local Minor Participants: 0

Protocol Title: Elite cyclists vs. untrained controls: comparing the VO2 kinetics response in young, middle aged and older men

Department \& Institution: Kinesiology,University of Western Ontario

Sponsor: Natural Sciences and Engineering Research Council

Ethics Approval Date: September 12, 2011

Expiry Date: August 31, 2012

Documents Reviewed \& Approved \& Documents Received for Information:

\begin{tabular}{|l|l|c|}
\hline Document Name & Comments & Version Date \\
\hline UWO Protocol & & \\
\hline Letter of Information \& Consent & & $2011 / 08 / 23$ \\
\hline Other & Script- Non student and student volunteers & \\
\hline
\end{tabular}

This is to notify you that the University of Western Ontario Health Sciences Research Ethics Board (HSREB) which is organized and operates according to the Tri-Council Policy Statement: Ethical Conduct of Research Involving Humans and the Health Canada/ICH Good Clinical Practice Practices: Consolidated Guidelines; and the applicable laws and regulations of Ontario has reviewed and granted approval to the above referenced study on the approval date noted above. The membership of this HSREB also complies with the membership requirements for REB's as defined in Division 5 of the Food and Drug Regulations.

The ethics approval for this study shall remain valid until the expiry date noted above assuming timely and acceptable responses to the HSREB's periodic requests for surveillance and monitoring information. If you require an updated approval notice prior to that time you must request it using the UWO Updated Approval Request form.

Member of the HSREB that are named as investigators in research studies, or declare a conflict of interest, do not participate in discussions related to, nor vote on, such studies when they are presented to the HSREB. 


\section{CURRICULUM VITAE}

Name: $\quad$ Tyler M. Grey,

B.Sc., M.Sc. Candidate

Post-secondary The University of Western Ontario

Education and London, Ontario, Canada

Degrees:

2012-2014 M.Sc. Kinesiology

The University of Western Ontario

London, Ontario, Canada

2007-2011 B.Sc. Kinesiology

Honours and

Awards:
Canadian Graduate Scholarship. Natural Sciences and Engineering Research Council (NSERC)

2013-2014

Western Graduate Research Scholarship

2012-2013, 2013-2014

Teaching Assistant

The University of Western Ontario

2009-2013

\section{Published Articles:}

Grey TM, Redguard DA, Wengle RS, Wegscheider PK. Effect of plantar flexor muscle fatigue on postural control (2013). Western Undergraduate Research Journal: Health and Natural Science. 3: 1-7.

Zerbini L, Spencer MD, Grey TM, Murias JM, Kowalchuk JM, Schena F, Paterson DH. Effect of acute hypoxia on muscle blood flow, $\mathrm{VO}_{2 \mathrm{p}}$, and $[\mathrm{HHb}]$ kinetics during leg extension exercise in older men (2013). Eur. J. Appl. Physiol. 113: 1685-1694.

Spencer MD, Murias JM, Grey TM, Paterson DH. Regulation of $\mathrm{VO}_{2}$ kinetics by $\mathrm{O}_{2}$ delivery: insights from acute hypoxia and heavy-intensity priming exercise in young men (2012). J. Appl. Physiol 112(6): 1023-1032.

\section{Published Abstracts:}

Grey TM, Spencer MD, Belfry GR, Paterson DH, and Murias JM (2013). The effect of age and training status on $\mathrm{VO}_{2}$ kinetics. Med Sci Sport Exer: 45(S5). 
Grey TM, Spencer MD, Murias JM, Kowalchuk JM, and Paterson DH (2012). Regulation of $\mathrm{VO}_{2}$ kinetics by $\mathrm{O}_{2}$ delivery: insights from acute hypoxia and heavy-intensity priming exercise in older men. Appl Physiol Nutr Metab: 37(S1).

Spencer MD, Murias JM, Grey TM, Paterson DH (2012). Aging does not affect the profile of muscle deoxygenation during ramp incremental exercise in chronically endurance trained men. $J$. Physiol. Proc Physiol Soc 26; PC 14.

Murias JM, Spencer MD, Grey TM, Paterson DH (2012). Chronic endurance training results in abolishment of the age-associated slower rate of adjustment of $\mathrm{VO}_{2}$ Kinetics. J. Physiol. Proc Physiol Soc 26; PC 102.

Spencer MD, Grey TM, Murias JM, Kowalchuk JM, and Paterson DH. (2011). Regulation of $\mathrm{VO}_{2}$ kinetics by $\mathrm{O}_{2}$ delivery: insights from acute hypoxia and heavy-intensity priming exercise in young men. Appl Physiol Nutr Metab. 36 Supp, s353.

Murias JM, Spencer MD, Grey TM, Gravelle BMR, and Paterson DH. (2011). $\Delta H H b / \mathrm{VO}_{2 p}$ ratio versus $\mathrm{Q}_{\text {cap }}$ : comparing two different methods for estimating the matching of blood flow to oxygen utilization. Appl Physiol Nutr Metab. 36 Supp, s340. 